\title{
Modeling the Interaction of Plastic Film Mulch and Potato Canopy Growth with Soil Heat Transport in a Semiarid Area
}

\author{
You-Liang Zhang ${ }^{1,2}$, Feng-Xin Wang ${ }^{2, *}$, Clinton C. Shock ${ }^{3}$ and Shao-Yuan Feng ${ }^{1,2}$ \\ 1 College of Hydraulic Science and Engineering, Yangzhou University, Yangzhou 225009, China; \\ youliangzhang@yzu.edu.cn (Y.-L.Z.); syfeng@yzu.edu.cn (S.-Y.F.) \\ 2 Center for Agricultural Water Research in China, China Agricultural University, No. 17 Qinghua East Road, \\ Haidian, Beijing 100083, China \\ 3 Oregon State University, Malheur Experiment Station, 595 Onion Ave., Ontario, OR 97914, USA; \\ clinton.shock@oregonstate.edu \\ * Correspondence: fxinwang@cau.edu.cn; Tel.: +86-010-6273-8523
}

Received: 9 December 2019; Accepted: 29 January 2020; Published: 31 January 2020

\begin{abstract}
Plastic film mulch is an important agricultural technology to reduce water evaporation and modify the soil thermal conditions for crop production. The optical properties of plastic film mulch and the crop canopy growth are both key factors impacting soil heat transport in the soil-film-canopy-atmosphere ecosystem. In this study, a process-oriented model was developed to better understand the interaction among the plastic film mulch, potato (Solanum tuberosum L.) canopy growth, and soil thermal conditions. Canopy growth, photosynthetically active radiation transmittance, net radiation, soil heat flux, and temperature were monitored in a two-year plastic mulch field experiment in Wuwei (Gansu Province, China). Results showed that the simulation of daily soil surface temperature had a good performance with 2.8 and $1.5^{\circ} \mathrm{C}$ of root mean square error (RMSE) for the transparent film mulch (TM) and black film mulch (BM), respectively. Moreover, the simulation of the daily net radiation and soil heat flux model indicated reasonable fluctuations with potato phenological development with the daily $R^{2}$ ranging from 0.89 to 0.98 in 2014 and 2015 for the TM and BM treatments. It was shown that the canopy temperature under BM was greater than that in TM treatment, and the maximum value difference could be up to $7^{\circ} \mathrm{C}$ during the early potato growing period, which implied that the BM may perform better in modifying the canopy thermal condition. The model could provide heat distribution information for plastic film choosing in potato field to avoid heat stress.
\end{abstract}

Keywords: plastic film mulch; canopy growth; heat transport; radiation transfer; potato field

\section{Introduction}

Plastic film mulch has been widely used in agriculture, especially in arid and semiarid regions, since it can save soil water by reducing evaporation [1] and optimize the light and thermal environments for crops [2-11]. Accordingly, plastic film mulching can improve seed emergence [12,13], root growth [14,15], nutrient uptake [16], stem elongation [5,11], final yield and water use efficiency [17-21].

The two widely used plastic films are black plastic film and transparent plastic film. Although both black plastic film (with high shortwave absorptance) and transparent plastic film (with high shortwave transmittance) can raise soil temperature [22], the effects of these two plastic films on plant growth can be contrary. For example, some researchers report that the use of black plastic film mulch leads to higher crop yield than transparent plastic film mulch $[12,23,24]$. Others report that transparent plastic film mulch results in higher crop yield than black plastic film mulch $[25,26]$. Such contradictory 
results are possible due to the complexity of heat transport in the soil-film-canopy-atmosphere system. Heat transport can be affected by the extent of contact between mulch and soil, the optical properties of the plastic film, and the geometry of the mulched surface [27].

Models have been developed to study heat transport considering different influencing factors since field experiments are time consuming and laborious. For example, some models have been developed to describe heat transport between soil, transparent plastic film mulch, and the atmosphere with energy balance equations considering the impacts of soil characteristics and the optical properties of mulch [28-30]. One validated heat transport model considers the effects of the optical properties of different plastic film mulches and the air gap between plastic film mulch and soil surface [6]. Since these models have limitations in simulating heat transport in field crops with plastic film mulch, other models have been developed. For example, Wu et al. [31] proposed a model to simulate soil temperature and water content in winter wheat (Triticum aestivum L.) with transparent plastic film mulch. This model mainly focuses on the distribution of soil temperature and water content. Yang et al. [32] added a plastic film mulch layer model into the SHAW model, constructed by Flerchinger et al. [33] and Flerchinger and Pierson [34], to consider the effects of plastic film mulch on heat transport in maize (Zea mays L.).

Although these models have been developed to study the effects of plastic film mulch on heat transport in fields with or without crops, some problems still need to be solved with new models. Heat stress, affecting the above-ground and below-ground parts growth of potato [35,36], can cause the low potato yield [37]. It is necessary to know the heat distribution for plastic film mulch choosing to provide optimal heat conditions for potato growth. One important problem is how to simulate the heat transport as the potato plant canopy changes. Zhang et al. [11] observed that the effects of transparent and black plastic film mulch on soil temperature in potato fields can be different in two growing seasons because of the different canopy growth. How can the interaction of canopy growth and the optical properties of plastic film mulch on heat transport be considered in the model?

The objective of this study was to develop a model to simulate the radiation, soil heat flux, and mulch surface and soil surface temperature at different potato growth stages considering the interaction of canopy growth and the optical properties of plastic film mulch. Leaf area index, canopy coverage, and photosynthetically active radiation transmittance were introduced in the model to account for the effects of plant canopy growth on heat transport. The model can be used to predict radiation, temperature, and soil heat flux in potato field and explain the effects of different plastic film mulches on potato growth during different growth stages.

\section{Materials and Methods}

\subsection{Study Area and Experimental Design}

The study area was located at the Shiyanghe Experimental Station (N $37^{\circ} 52^{\prime}, \mathrm{E} 102^{\circ} 50^{\prime}$, altitude $1581 \mathrm{~m})$, China Agricultural University, Wuwei, Gansu Province, on the border of the Tenger Desert with a typical continental temperate climate. The area has sufficient heat resources and limited water resources with mean annual temperature $8{ }^{\circ} \mathrm{C}$, annual accumulated temperature $\left(>0{ }^{\circ} \mathrm{C}\right) 3550{ }^{\circ} \mathrm{C}$, annual sunshine duration $3000 \mathrm{~h}$, annual precipitation $164 \mathrm{~mm}$, pan evaporation $2000 \mathrm{~mm}$, and groundwater table 5-30 m below ground surface [38]. The soil texture is sandy loam with mean soil bulk density $1.53 \mathrm{~g} / \mathrm{cm}^{3}$ at $0-1.0 \mathrm{~m}$ depth [11].

To calibrate and verify the model, experiments were conducted in potato fields from April to August in 2014 and 2015. Two soil surface treatments were compared: transparent plastic film mulch (TM) and black plastic film mulch (BM), each with a thickness of $0.008 \mathrm{~mm}$. The soil surface of each treatment was fully covered with polyethylene (PE) plastic film. Each treatment was replicated three times in a randomized complete block design. 


\subsection{Agronomic and Irrigation Practices}

As the agronomic and irrigation practices have been described in detail by Zhang et al. [11], only a general introduction is presented here to avoid repetition. In the first year the potatoes were planted on 22 April and harvested on 21 August 2014. Since the weather was warm earlier in 2015, the potatoes were planted on 15 April and harvested on 20 August. The plot size was $6 \mathrm{~m}$ long and $5.6 \mathrm{~m}$ wide with 7 beds ( $0.8 \mathrm{~m}$ wide and $0.2 \mathrm{~m}$ high). The potato crop was irrigated using a drip irrigation system with drip tape placed under the plastic mulch on the center of the beds. Irrigation was initiated when the soil matric potentials measured with tensiometers reached $-25 \mathrm{kPa}$. The specific irrigation information has been shown by Zhang et al. [11].

\subsection{Measurements}

Ten plants in each plot were labeled for height measurement every 7 days (fewer than 7 days during vigorous plant growth). The leaves of five plants in two plots were collected to measure leaf area index in 2014. Total leaf weight and the weight of 30 typical leaves were measured. To reduce labor intensity only the area of the 30 typical leaves was measured with the AM300 (ADC BioScientific Ltd., Hertfordshire, UK) a portable leaf area meter. The total leaf area per plant was calculated using the ratio between the weight of the 30 leaves and the total leaf weight.

The fractional canopy coverage, proportion of the ground covered by potato canopy $\left(P_{\mathrm{cc}}\right)$, was determined with digital images which were taken at a height of $2 \mathrm{~m}$ above ground using a Canon IXUS 132 digital camera (Canon Inc., Tokyo, Japan) [39,40]. The images were taken at 12:00-13:00 to minimize shadows. A typical region $(1.6 \mathrm{~m} \times 0.9 \mathrm{~m})$ containing two rows (row spacing $0.8 \mathrm{~m}$ ) with 6 plants (plant spacing $0.3 \mathrm{~m}$ ) was selected in each plot to take photographs. The plants were captured in the images using quick selection tool, magic wand tool, and lasso tool of Adobe Photoshop CS5 (Adobe Systems Inc., San Jose, CA, USA). Then, the images were processed into black and white binary image (black pixels denote plants) with the Adobe Photoshop CS5. The proportion of black pixels in the image, read from the Adobe Photoshop CS5 histogram represented the fractional canopy coverage. The example of images before and after processing is shown in Figure 1.
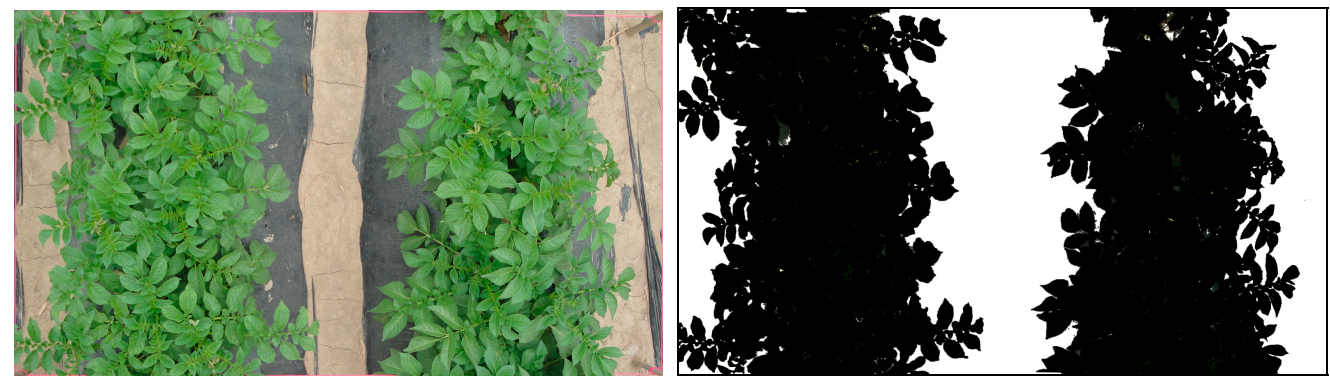

Figure 1. Example of potato canopy cover images taken at Wuwei, China on 2 June 2015 before and after processing for obtaining fractional canopy coverage.

The photosynthetically active radiation transmittance of the potato canopy $\left(T_{\text {par }}\right)$ was measured with SunScan Canopy Analysis System (Delta-T Devices Ltd., Cambridge, UK) at 12:00-13:00 on a sunny day. Given the inhomogeneity of the potato canopy, the SunScan probe was placed on the bed (perpendicular to the row direction) at 7 random positions for each plot. The average of the transmittance was recorded.

Temperatures on the plastic film mulch surface, on the soil surface, and at 0.05 and $0.1 \mathrm{~m}$ soil depths were measured with sensors in the middle of the beds in one replication of each treatment. The sensors on the plastic film mulch surface, on the soil surface, and at $0.05 \mathrm{~m}$ soil depth were $0.25-\mathrm{mm}$ copper-constantan thermocouples (ST10, Beijing Unism Technologies, Inc., Beijing, China). The sensors at $0.1 \mathrm{~m}$ soil depth were soil temperature/water sensors (FDS120, Beijing Unism Technologies, Inc.). 
Weather variables were measured with a standard automatic weather station (HOBO H21-001, Onset Computer Corp., Cape Cod, MA, USA), $2 \mathrm{~m}$ aboveground. The measurable weather variables consisted of global radiation, wind speed, relative humidity, air temperature, atmospheric pressure, and precipitation. Global radiation and air temperature has been shown in previous report of Zhang et al. [11]. Net radiation above the canopy was measured with net radiometers (NR Lite2, Kipp\&Zonen, Delft, Netherlands), installed in the middle of one replication of each treatment.

Soil heat fluxes at $0.05 \mathrm{~m}$ soil depth in the middle of the bed were monitored in one replication of each treatment using soil heat flux plates (HFP01, Hukseflux, Delft, The Netherlands). According to Giambelluca et al. [41] the soil heat flux on the soil surface can be estimated as follows:

$$
\begin{gathered}
G=F+M \\
M=\frac{\Delta T_{s}}{t} d\left(\rho_{b} C_{s}+\rho_{w} \theta C_{w}\right)
\end{gathered}
$$

where $G$ is the soil heat flux on the soil surface $\left(\mathrm{W} / \mathrm{m}^{2}\right)$ (W is the amount of energy received per second), $F$ is the soil heat flux at $0.05 \mathrm{~m}$ soil depth $\left(\mathrm{W} / \mathrm{m}^{2}\right), M$ is the soil heat flux change between soil surface and soil heat flux sensor $\left(\mathrm{W} / \mathrm{m}^{2}\right), t$ is the time interval (s) $(1800 \mathrm{~s}), \Delta T_{s}$ is the soil temperature change in the 0 to $0.05 \mathrm{~m}$ soil layer during the time interval $t\left({ }^{\circ} \mathrm{C}\right), d$ is the distance between the soil surface and soil heat flux sensor $(\mathrm{m})(0.05 \mathrm{~m}), \rho_{b}$ is the soil dry bulk density $\left(\mathrm{kg} / \mathrm{m}^{3}\right)\left(1530 \mathrm{~kg} / \mathrm{m}^{3}\right), \rho_{\mathrm{w}}$ is the water density $\left(\mathrm{kg} / \mathrm{m}^{3}\right), C_{s}$ is the soil specific heat $\left[\mathrm{J} /\left(\mathrm{kg}^{\circ} \mathrm{C}\right)\right]\left[840 \mathrm{~J} /\left(\mathrm{kg}^{\circ} \mathrm{C}\right)\right], C_{\mathrm{w}}$ is the water specific heat $\left[\mathrm{J} /\left(\mathrm{kg}{ }^{\circ} \mathrm{C}\right)\right]$, and $\theta$ is the volumetric soil water content in the 0 to $0.05 \mathrm{~m}$ soil layer $\left(\mathrm{m}^{3} / \mathrm{m}^{3}\right.$ ) (where the volumetric soil water content at $0.1 \mathrm{~m}$ soil depth is used as an approximation).

The temperature sensors were connected to a data logger (SMC6108, Beijing Unism Technologies, Inc.). The net radiometers and soil heat flux plates were connected to another data logger (CR1000, Campbell Scientific Inc., Logan, UT, USA). The measurements were sampled at $10 \mathrm{~s}$ intervals and the averages were stored every $10 \mathrm{~min}$.

\section{Description of the Model}

\subsection{Energy Balance Equations}

The energy transport in potato fields with plastic film mulch is illustrated in Figure 2. According to Ham and Kluitenberg [6], these assumptions are made for the model: (1) Soil evaporation is neglected because of the full plastic film mulch. Although soil evaporation still occurs at the hole of plant emergence, the evaporation is quite small compared with plant transpiration; (2) There is no heat stored in the plastic film mulch and plant; and (3) Heat transfer in the process of evaporation/condensation between plastic film mulch and soil is neglected. Thus, the energy balance of the plant canopy can be expressed as follows:

$$
R_{n c}-H_{c a}-\lambda T+H_{m c}=0
$$

where $R_{n c}$ is the net radiation absorbed by the plant canopy $\left(\mathrm{W} / \mathrm{m}^{2}\right), H_{c a}$ is the sensible heat flux from the plant canopy to the atmosphere $\left(\mathrm{W} / \mathrm{m}^{2}\right), \lambda T$ is the latent heat flux of the plant canopy $\left(\mathrm{W} / \mathrm{m}^{2}\right)$, and $H_{m c}$ is the sensible heat flux from the plastic film mulch to the plant canopy $\left(\mathrm{W} / \mathrm{m}^{2}\right)$.

According to Ham and Kluitenberg [6], the energy balance of the plastic film mulch can be defined as follows:

$$
R_{n m}-H_{m c}+C_{s m}=0
$$

where $R_{n m}$ is the net radiation absorbed by the plastic film mulch $\left(\mathrm{W} / \mathrm{m}^{2}\right)$, and $C_{s m}$ is the conduction from the soil surface to the plastic film mulch $\left(\mathrm{W} / \mathrm{m}^{2}\right)$. The energy balance of the soil surface can be defined as follows:

$$
R_{n s}-C_{s m}-G=0
$$


where $R_{n s}$ is the net radiation absorbed by the soil surface $\left(\mathrm{W} / \mathrm{m}^{2}\right)$, and $G$ is the soil heat flux at the soil surface $\left(\mathrm{W} / \mathrm{m}^{2}\right)$.

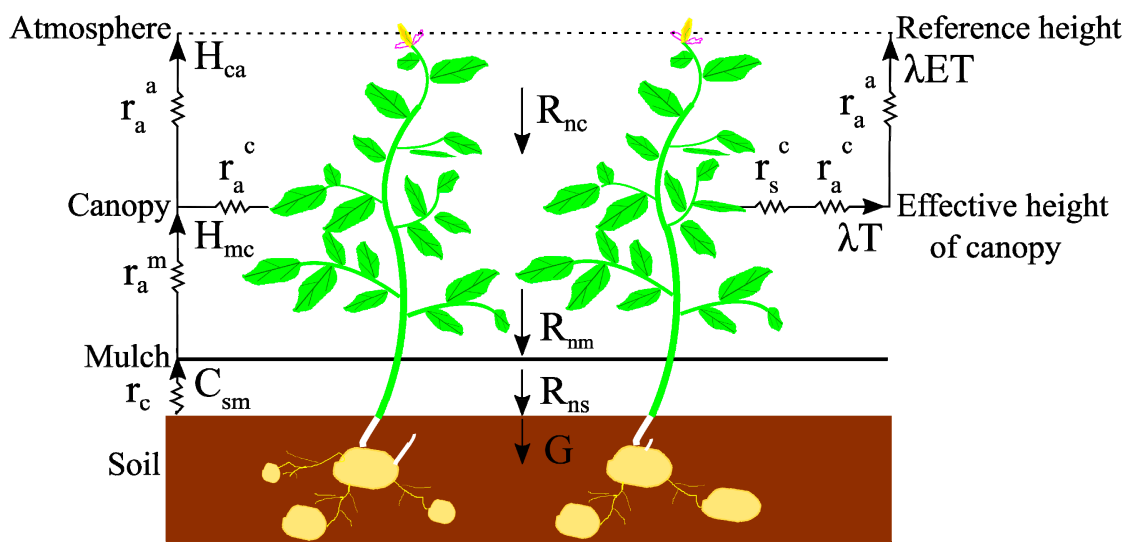

Figure 2. Schematic diagram of energy transport in a potato field with plastic film mulch $\left(R_{n c}, R_{n m}\right.$, and $R_{n s}$ are the net radiations absorbed by the plant canopy, the plastic film mulch, and the soil surface, respectively; $H_{c a}$ is the sensible heat flux from the plant canopy to the atmosphere; $H_{m c}$ is the sensible heat flux from the plastic film mulch to the plant canopy; $C_{s m}$ is the conduction from the soil surface to the plastic film mulch; $G$ is the soil heat flux at the soil surface; $\lambda T$ is the latent heat flux of the plant canopy; $\lambda E T$ is the latent heat flux of complete canopy; $r_{s}^{c}$ is the bulk stomatal resistance of the plant canopy; $r_{a}^{c}$ is the bulk boundary layer resistance of the vegetative elements in the plant canopy; $r_{a}^{a}$ is the aerodynamic resistance between the plant canopy and the reference height; $r_{a}^{m}$ is the aerodynamic resistance between the plastic film mulch and the plant canopy; $r_{c}$ is the thermal contact resistance between the plastic mulch and soil).

\subsubsection{Governing Equations for Net Radiation of Each Layer}

The radiation transfer is more complicated in the soil-film-canopy-atmosphere system than the soil-film-atmosphere system. The physical representation of the shortwave radiation transfer can be described in Figure 3.

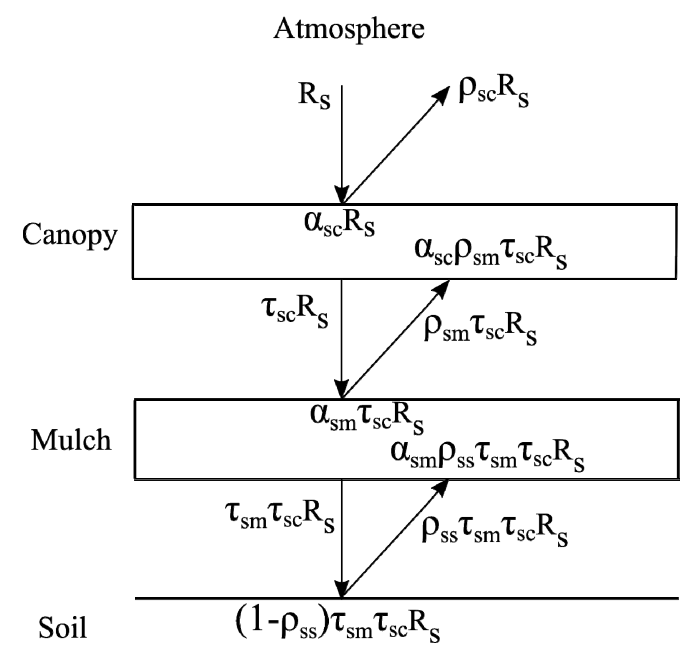

Figure 3. Schematic diagram of shortwave radiation transfer in the potato canopy, plastic film mulch, and soil surface $\left(R_{s}\right.$ is the global radiation; $\alpha_{s c}$ and $\alpha_{s m}$ are the shortwave absorptances of the plant canopy and plastic film mulch, respectively; $\rho_{S m}$ and $\rho_{S S}$ are the shortwave reflectances of the plastic film mulch and soil, respectively; and $\tau_{s c}$ and $\tau_{s m}$ are the shortwave transmittances of the plant canopy and plastic film mulch, respectively). 
The shortwave radiation $R_{s c}, R_{s m}$, and $R_{s s}$ absorbed by the plant canopy, the plastic film mulch, and the soil surface can be described as follows:

$$
\begin{gathered}
R_{s c}=\alpha_{s c} R_{s}+\alpha_{s c} \rho_{s m} \tau_{s c} R_{s} \\
R_{s m}=\alpha_{s m} \tau_{s c} R_{s}+\alpha_{s m} \rho_{s s} \tau_{s m} \tau_{s c} R_{s} \\
R_{s s}=\left(1-\rho_{s s}\right) \tau_{s m} \tau_{s c} R_{s}
\end{gathered}
$$

where $R_{s}$ is the global radiation $\left(\mathrm{W} / \mathrm{m}^{2}\right) ; \alpha_{s c}$ and $\alpha_{s m}$ are the shortwave absorptances of the plant canopy and plastic film mulch, respectively; $\rho_{s m}$ and $\rho_{s s}$ are the shortwave reflectances of the plastic film mulch and soil, respectively; and $\tau_{s c}$ and $\tau_{s m}$ are the shortwave transmittances of the plant canopy and plastic film mulch, respectively.

As shown in Figure $4 \mathrm{a}-\mathrm{d}$, the longwave radiation $R_{l c}, R_{l m}$, and $R_{l s}$ absorbed by the plant canopy, the plastic film mulch, and the soil surface can be described as follows:

$$
\begin{gathered}
R_{l c}=\varepsilon_{c} \varepsilon_{s k y} \sigma T_{s k y}^{4}\left(1+\rho_{l m} \tau_{l c}\right)+\varepsilon_{c} \sigma T_{c}^{4}\left(\rho_{l m} \varepsilon_{c}-2\right)+\varepsilon_{c} \varepsilon_{m} \sigma T_{m}^{4}+\varepsilon_{c} \tau_{l m} \varepsilon_{s} \sigma T_{s}^{4} \\
R_{l m}=\varepsilon_{m} \tau_{l c} \varepsilon_{s k y} \sigma T_{s k y}^{4}\left[1+\left(1-\varepsilon_{s}\right) \tau_{l m}\right]+\varepsilon_{m} \varepsilon_{c} \sigma T_{c}^{4}\left[1+\left(1-\varepsilon_{s}\right) \tau_{l m}\right]+ \\
\varepsilon_{m} \sigma T_{m}^{4}\left[\rho_{l c} \varepsilon_{m}+\left(1-\varepsilon_{s}\right) \varepsilon_{m}-2\right]+\varepsilon_{m} \varepsilon_{s} \sigma T_{s}^{4}\left(1+\rho_{l c} \tau_{l m}\right) \\
R_{l s}=\varepsilon_{s} \tau_{l m} \tau_{l c} \varepsilon_{s k y} \sigma T_{s k y}^{4}+\varepsilon_{s} \tau_{l m} \varepsilon_{c} \sigma T_{c}^{4}+\varepsilon_{s} \varepsilon_{m} \sigma T_{m}^{4}+\varepsilon_{s} \sigma T_{s}^{4}\left(\varepsilon_{s} \rho_{l m}-1\right)
\end{gathered}
$$

where $\sigma$ is the Stefan-Boltzmann constant $\left[\mathrm{W} /\left(\mathrm{m}^{2}{ }^{\circ} \mathrm{C}^{4}\right)\right] ; T_{\text {sky }}$ (set equal to the air temperature) [6], $T_{\mathcal{C}}$, $T_{m}$, and $T_{s}$ are the temperatures of the sky, plant canopy, plastic film mulch, and soil surface $\left({ }^{\circ} \mathrm{C}\right)$, respectively; $\varepsilon_{s k y}, \varepsilon_{\mathcal{c}}, \varepsilon_{m}$, and $\varepsilon_{s}$ are the emissivities (or infrared absorptances) of the sky, plant canopy, plastic film mulch, and soil surface, respectively; $\rho_{l m}$ and $\rho_{l c}$ are the longwave reflectances of the plastic film mulch and plant canopy, respectively; and $\tau_{l c}$ and $\tau_{l m}$ are the longwave transmittances of the plant canopy and plastic film mulch, respectively.

Then, the net radiation $R_{n c}, R_{n m}$, and $R_{n s}$ absorbed by the plant canopy, the plastic film mulch, and the soil surface can be expressed as:

$$
\begin{gathered}
R_{n c}=\alpha_{s c} R_{s}\left(1+\rho_{s m} \tau_{s c}\right)+\varepsilon_{c} \varepsilon_{s k y} \sigma T_{s k y}^{4}\left(1+\rho_{l m} \tau_{l c}\right)+\varepsilon_{c} \sigma T_{c}^{4}\left(\rho_{l m} \varepsilon_{c}-2\right)+ \\
\varepsilon_{c} \varepsilon_{m} \sigma T_{m}^{4}+\varepsilon_{c} \tau_{l m} \varepsilon_{s} \sigma T_{s}^{4} \\
R_{n m}=\alpha_{s m} \tau_{s c} R_{s}\left(1+\rho_{s s} \tau_{s m}\right)+\varepsilon_{m} \tau_{l c} \varepsilon_{s k y} \sigma T_{s k y}^{4}\left[1+\left(1-\varepsilon_{s}\right) \tau_{l m}\right]+\varepsilon_{m} \varepsilon_{c} \sigma T_{c}^{4}\left[1+\left(1-\varepsilon_{s}\right) \tau_{l m}\right] \\
+\varepsilon_{m} \sigma T_{m}^{4}\left[\rho_{l c} \varepsilon_{m}+\left(1-\varepsilon_{s}\right) \varepsilon_{m}-2\right]+\varepsilon_{m} \varepsilon_{s} \sigma T_{s}^{4}\left(1+\rho_{l c} \tau_{l m}\right) \\
R_{n s}=\left(\begin{array}{c}
\left(1-\rho_{s s}\right) \tau_{s m} \tau_{s c} R_{s}+\varepsilon_{s} \tau_{l m} \tau_{l c} \varepsilon_{s k y} \sigma T_{s k y}^{4}+\varepsilon_{s} \tau_{l m} \varepsilon_{c} \sigma T_{c}^{4}+\varepsilon_{s} \varepsilon_{m} \sigma T_{m}^{4} \\
+\varepsilon_{s} \sigma T_{s}^{4}\left(\varepsilon_{s} \rho_{l m}-1\right)
\end{array}\right.
\end{gathered}
$$

\subsubsection{Governing Equations for Latent Heat Flux}

According to Kang et al. (page 39) [42] the latent heat flux from the plant canopy can be defined as follows:

$$
\lambda T=\frac{\rho_{a} c_{p}}{\gamma}\left[\left(e_{s}-e_{a}\right)+\Delta\left(T_{c}-T_{a}\right)\right] /\left(r_{s}^{c}+r_{a}^{c}\right)
$$

where $\rho_{a}$ is the density of air $\left(\mathrm{kg} / \mathrm{m}^{3}\right), c_{p}$ is the specific heat at constant pressure $\left[\mathrm{J} /\left(\mathrm{kg}{ }^{\circ} \mathrm{C}\right)\right], \gamma$ is the psychrometric constant $\left(\mathrm{kPa} /{ }^{\circ} \mathrm{C}\right), T_{\mathcal{c}}$ is the temperature of the plant canopy $\left({ }^{\circ} \mathrm{C}\right), T_{\mathrm{a}}$ is the air temperature $\left({ }^{\circ} \mathrm{C}\right), e_{s}$ is the saturation vapour pressure $(\mathrm{kPa}), e_{a}$ is the actual vapour pressure $(\mathrm{kPa}), \Delta$ is the slope of the vapour pressure curve $\left(\mathrm{kPa} /{ }^{\circ} \mathrm{C}\right), r_{s}^{c}$ is the bulk stomatal resistance of the plant canopy $(\mathrm{s} / \mathrm{m})$, and $r_{a}^{c}$ is the bulk boundary layer resistance of the vegetative elements in the plant canopy $(\mathrm{s} / \mathrm{m})$. 
The bulk stomatal resistance $r_{s}^{c}$ and $r_{a}^{c}$ are suggested by Shuttleworth and Wallace [43] as follows:

$$
\begin{aligned}
& r_{s}^{c}=\frac{r_{S T}}{2 L A I} \\
& r_{a}^{c}=\frac{r_{b}}{2 L A I}
\end{aligned}
$$

where $r_{S T}$ is the mean stomatal resistance $(\mathrm{s} / \mathrm{m}), r_{b}$ is the mean boundary layer resistance $(\mathrm{s} / \mathrm{m})$, and $L A I$ is the leaf area index.
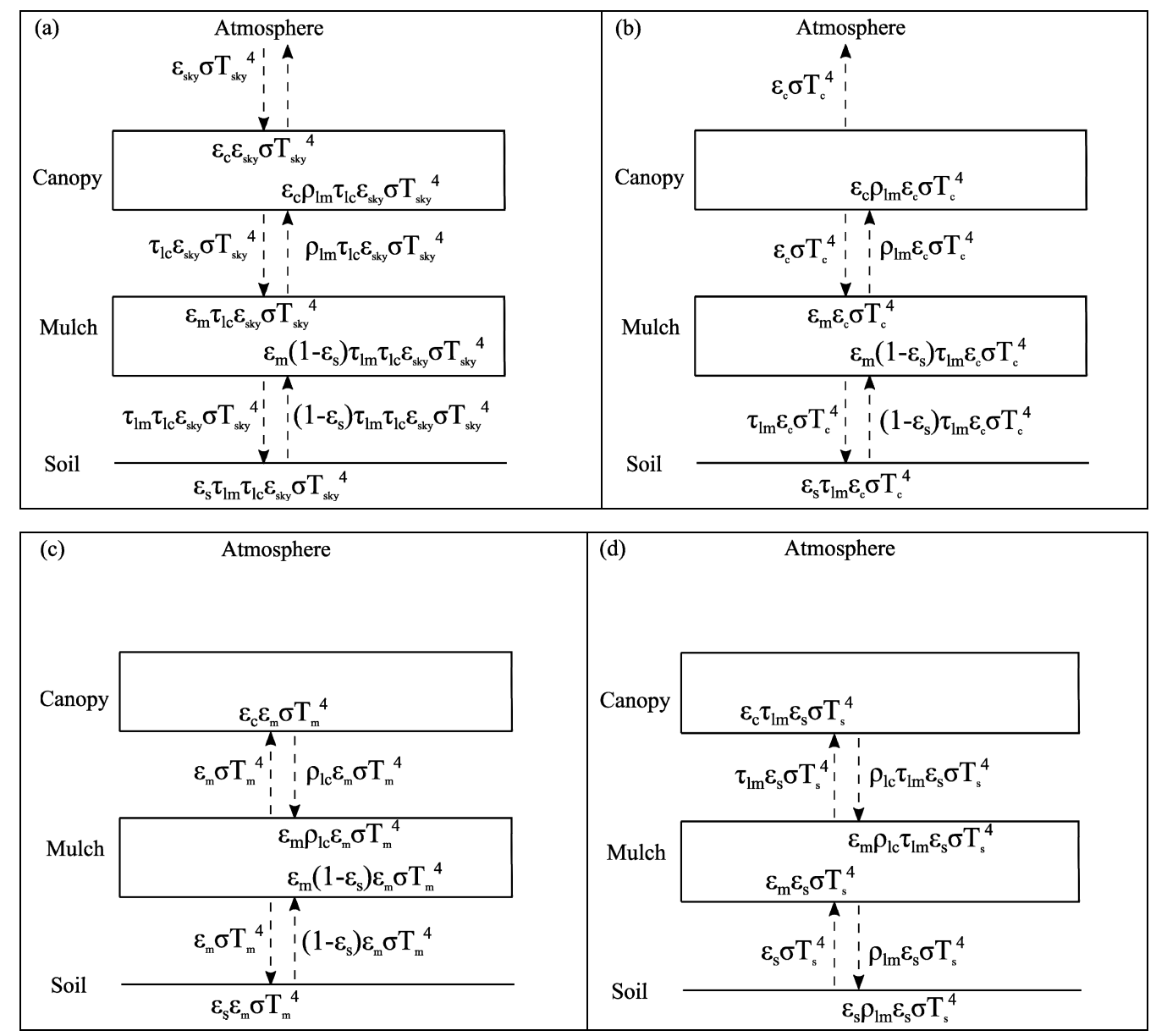

Figure 4. Schematic diagram of emitted longwave radiation transfer between the potato canopy, plastic film mulch, and soil surface from: (a) the atmosphere, (b) the potato canopy, (c) the plastic film mulch, and (d) the soil surface ( $\sigma$ is the Stefan-Boltzmann constant; $T_{s k y}, T_{\mathcal{c}}, T_{m}$, and $T_{s}$ are the temperatures of the sky, plant canopy, plastic film mulch, and soil surface, respectively; $\varepsilon_{s k y}, \varepsilon_{c}, \varepsilon_{m}$, and $\varepsilon_{S}$ are the emissivities (or infrared absorptances) of the sky, plant canopy, plastic film mulch, and soil surface, respectively; $\rho_{l m}$ and $\rho_{l c}$ are the longwave reflectances of the plastic film mulch and plant canopy, respectively; and $\tau_{l c}$ and $\tau_{l m}$ are the longwave transmittances of the plant canopy and plastic film mulch, respectively).

\subsubsection{Governing Equations for Sensible Heat Flux}

The sensible heat flux can be defined as follows:

$$
H_{c a}=\frac{\rho_{a} c_{p}\left(T_{c}-T_{a}\right)}{r_{a}^{a}}
$$




$$
H_{m c}=\frac{\rho_{a} c_{p}\left(T_{m}-T_{c}\right)}{r_{a}^{m}}
$$

where $T_{m}$ is the temperature of the plastic film mulch $\left({ }^{\circ} \mathrm{C}\right), r_{a}^{a}$ is the aerodynamic resistance between the plant canopy and the reference height $(\mathrm{s} / \mathrm{m})$, and $r_{a}^{m}$ is the aerodynamic resistance between the plastic film mulch and the plant canopy $(\mathrm{s} / \mathrm{m})$.

The aerodynamic resistances $r_{a}^{a}$ and $r_{a}^{m}$ are given by Shuttleworth and Wallace [43] as follows:

$$
\begin{aligned}
& \left.\begin{array}{rl}
r_{a}^{a} & =\frac{1}{4} L A I r_{a}^{a}(\alpha)+\frac{1}{4}(4-L A I) r_{a}^{a}(0) \\
r_{a}^{m} & =\frac{1}{4} L A I r_{a}^{m}(\alpha)+\frac{1}{4}(4-L A I) r_{a}^{m}(0)
\end{array}\right\} 0 \leq L A I \leq 4 \\
& \left.\begin{array}{rl}
r_{a}^{a} & =r_{a}^{a}(\alpha) \\
r_{a}^{m} & =r_{a}^{m}(\alpha)
\end{array}\right\} L A I>4
\end{aligned}
$$

where $r_{a}^{a}(\alpha)$ and $r_{a}^{m}(\alpha)$ are the values of $r_{a}^{a}$ and $r_{a}^{m}$, respectively, when the ground is covered fully by a crop canopy $(\mathrm{s} / \mathrm{m})$; and $r_{a}^{a}(0)$ and $r_{a}^{m}(0)$ are the values of $r_{a}^{a}$ and $r_{a}^{m}$, respectively, when there is no crop $(\mathrm{s} / \mathrm{m})$.

The $r_{a}^{a}(\alpha)$ and $r_{a}^{m}(\alpha)$ can be expressed as follows:

$$
\left.\begin{array}{l}
r_{a}^{a}(\alpha)=\frac{\ln \left[\left(h_{r}-d\right) / z_{0}\right]}{k^{2} u}\left\langle\ln \left[\left(h_{r}-d\right) /\left(h_{p}-d\right)\right]+\frac{h_{p}}{n\left(h_{p}-d\right)} \times\left\{\exp \left[n\left(1-\frac{d+z_{0}}{h_{p}}\right)\right]-1\right\}\right\rangle \\
r_{a}^{m}(\alpha)=\frac{\ln \left[\left(h_{r}-d\right) / z_{0}\right]}{k^{2} u} \frac{h_{p}}{n\left(h_{p}-d\right)}\left\langle\exp n-\exp \left\{n\left[1-\left(d+z_{0}\right) / h_{p}\right]\right\}\right\rangle
\end{array}\right\}
$$

where $h_{r}$ is the reference height (m), $u$ is the wind speed at the reference height $(\mathrm{m} / \mathrm{s}), n$ is the eddy diffusivity decay constant when the ground is fully covered by crop, $k$ is von Kármán's constant, $h_{p}$ is the plant height $(\mathrm{m}), d$ is the zero plane displacement when the ground is covered by crop fully $(\mathrm{m})$, and $z_{0}$ is the roughness height when the ground is covered fully by a crop canopy $(\mathrm{m})$. The $d$ and $z_{0}$ can be given as follows:

$$
\begin{aligned}
d & =0.63 h_{p} \\
z_{0} & =0.13 h_{p}
\end{aligned}
$$

The $r_{a}^{a}(0)$ and $r_{a}^{m}(0)$ can be expressed as follows:

$$
\left.\begin{array}{l}
r_{a}^{a}(0)=\frac{\ln ^{2}\left(h_{r} / z_{0}{ }^{\prime}\right)}{k^{2} u}-r_{a}^{m}(0) \\
r_{a}^{m}(0)=\frac{\ln \left(h_{r} / z_{0}{ }^{\prime}\right) \ln \left[\left(d+z_{0}\right) / z_{0}{ }^{\prime}\right]}{k^{2} u}
\end{array}\right\}
$$

where $z_{0}^{\prime}$ is the roughness height when there is no crop $(\mathrm{m})$.

\subsubsection{Governing Equations for Soil Heat Flux}

The soil heat flux $G$ suggested by Horton and Chung [44] is as follows:

$$
G=-\lambda \frac{T_{l}^{n-1}-T_{s}^{n}}{\Delta z}+C \frac{\left(T_{s}^{n}-T_{s}^{n-1}\right) \Delta z}{2 \Delta t}
$$

where $T_{S}$ is the temperature of the soil surface $\left({ }^{\circ} \mathrm{C}\right), T_{l}$ is the temperature of the first vertical node below the soil surface $\left({ }^{\circ} \mathrm{C}\right), \Delta z$ is the distance between the soil surface and the first vertical node $(\mathrm{m}), \Delta t$ is the time step increment (s), $n$ is the time step number, $C$ is the volumetric soil heat capacity $\left[\mathrm{J} /\left(\mathrm{m}^{3}{ }^{\circ} \mathrm{C}\right)\right], \lambda$ is the soil thermal conductivity $\left[\mathrm{W} /\left(\mathrm{m}^{\circ} \mathrm{C}\right)\right]$.

The volumetric soil heat capacity $C$ is given by de Vries [45] as follows:

$$
C \approx\left(1.92 \theta_{n}+2.51 \theta_{o}+4.18 \theta\right) \times 10^{6}
$$


where $\theta_{n}$ is the solid phase content, $\theta_{0}$ is the organic matter content, and $\theta$ is the volumetric soil water content $\left(\mathrm{m}^{3} / \mathrm{m}^{3}\right)$.

According to Chung and Horton [46] the soil thermal conductivity $\lambda$ can be estimated as follows:

$$
\lambda=b_{1}+b_{2} \theta+b_{3} \theta^{0.5}
$$

where $b_{1}, b_{2}$, and $b_{3}$ are empirical parameters $\left[\mathrm{W} /\left(\mathrm{m}^{\circ} \mathrm{C}\right)\right]$.

\subsubsection{Governing Equations for Conduction From the Soil Surface to the Plastic Film Mulch}

The heat conduction from the soil surface to the plastic film mulch $C_{s m}$ is given by Ham Kluitenberg [6] as follows:

$$
C_{s m}=\frac{T_{s}-T_{m}}{r_{c}}
$$

where $r_{c}$ is the thermal contact resistance between the plastic mulch and soil $\left(\mathrm{m}^{2}{ }^{\circ} \mathrm{C} / \mathrm{W}\right)$. According to Ham Kluitenberg [6] the conduction is dominated by heat transfer when the distance between the plastic film mulch and soil is less than $0.01 \mathrm{~m}$. Then the $r_{c}$ can be defined as follows:

$$
r_{c}=\frac{z_{g}}{k_{a} N_{u d}}
$$

where $z_{g}$ is the distance between the plastic film mulch and the soil $(\mathrm{m}), k_{a}$ is the air thermal conductivity $\left[\mathrm{W} /\left(\mathrm{m}^{\circ} \mathrm{C}\right)\right]$, and $N_{u d}$ is the Nusselt number reflecting the regime of conduction.

In summary, the energy balance Equations (3)-(5) can be expressed as follows:

$$
\begin{gathered}
\alpha_{s c} R_{s}\left(1+\rho_{s m} \tau_{s c}\right)+\varepsilon_{c} \varepsilon_{s k y} \sigma T_{s k y}^{4}\left(1+\rho_{l m} \tau_{l c}\right)+\varepsilon_{c} \sigma T_{c}^{4}\left(\rho_{l m} \varepsilon_{c}-2\right)+\varepsilon_{c} \varepsilon_{m} \sigma T_{m}^{4}+\varepsilon_{c} \tau_{l m} \varepsilon_{s} \sigma T_{s}^{4} \\
-\rho_{a} c_{p}\left(T_{c}-T_{a}\right) / r_{a}^{a}-\frac{\rho_{a} c_{p}}{\gamma}\left[\left(e_{s}-e_{a}\right)+\Delta\left(T_{c}-T_{a}\right)\right] /\left(r_{s}^{c}+r_{a}^{c}\right)+\rho_{a} c_{p}\left(T_{m}-T_{c}\right) / r_{a}^{m}=0 \\
\alpha_{s m} \tau_{s c} R_{s}\left(1+\rho_{s s} \tau_{s m}\right)+\varepsilon_{m} \tau_{l c} \varepsilon_{s k y} \sigma T_{s k y}^{4}\left[1+\left(1-\varepsilon_{s}\right) \tau_{l m}\right]+\varepsilon_{m} \varepsilon_{c} \sigma T_{c}^{4}\left[1+\left(1-\varepsilon_{s}\right) \tau_{l m}\right]+\varepsilon_{m} \sigma T_{m}^{4}\left[\rho_{l c} \varepsilon_{m}\right. \\
\left.+\left(1-\varepsilon_{s}\right) \varepsilon_{m}-2\right]+\varepsilon_{m} \varepsilon_{s} \sigma T_{s}^{4}\left(1+\rho_{l c} \tau_{l m}\right)-\rho_{a} c_{p}\left(T_{m}-T_{c}\right) / r_{a}^{m}+\left(T_{s}-T_{m}\right) / r_{c}=0 \\
\left(1-\rho_{s s}\right) \tau_{s m} \tau_{s c} R_{s}+\varepsilon_{s} \tau_{l m} \tau_{l c} \varepsilon_{s k y} \sigma T_{s k y}^{4}+\varepsilon_{s} \tau_{l m} \varepsilon_{c} \sigma T_{c}^{4}+\varepsilon_{s} \varepsilon_{m} \sigma T_{m}^{4}+\varepsilon_{s} \sigma T_{s}^{4}\left(\varepsilon_{s} \rho_{l m}-1\right) \\
-\left(T_{s}-T_{m}\right) / r_{c}+\lambda\left(T_{l}^{n-1}-T_{s}^{n}\right) / \Delta z-C \Delta z\left(T_{s}^{n}-T_{s}^{n-1}\right) /(2 \Delta t)=0
\end{gathered}
$$

\subsection{Parameterization for the Energy Balance Equations}

As many parameters were involved in the energy balance equations, the parameterization for the net radiation, latent heat flux, and heat conduction were introduced separately.

\subsubsection{Parameterization for Net Radiation}

\section{Net Radiation of the Plant Canopy}

The global radiation $\left(R_{s}\right)$ was measured with the weather station. The shortwave transmittance of the potato canopy $\left(\tau_{s c}\right)$ is supposed to be equal to the photosynthetically active radiation transmittance $\left(T_{p a r}\right)$. According to Haverkort et al. [47] the shortwave reflectance of potato canopy can be approximated as follows:

$$
\rho_{s c}=0.314 P_{c c}+0.203
$$

where $\rho_{s c}$ is the shortwave reflectance of the potato canopy and $P_{c c}$ is the canopy coverage. Then the shortwave absorptance of the potato canopy $\left(\alpha_{s c}\right)$ is:

$$
\alpha_{s c}=1-\tau_{s c}-\rho_{s c}
$$


The emissivity (or infrared absorptance) of the potato canopy $\left(\varepsilon_{c}\right)$ is 0.97 when the ground is covered fully by the canopy [27]. The relationship between $\varepsilon_{c}$ and $P_{c c}$ can be assumed as follows:

$$
\varepsilon_{\mathcal{c}}=0.97 P_{c \mathcal{c}}
$$

The longwave reflectance of the potato canopy $\left(\rho_{l c}\right)$ is about 0.01 [27]. According to Ham Kluitenberg [6] the longwave transmittance of potato canopy $\left(\tau_{l c}\right)$ is approximated as follows:

$$
\tau_{l c}=1-0.01-0.97 P_{c c}
$$

Net Radiation of the Plastic Film Mulch

The shortwave absorptance $\left(\alpha_{s m}\right)$ and the shortwave transmittance $\left(\tau_{s m}\right)$ of the plastic film mulch were determined through parameter calibration with the field experiment data. The shortwave reflectance of the plastic film mulch $\left(\rho_{s m}\right)$ can be obtained by the equation:

$$
\rho_{s m}=1-\alpha_{s m}-\tau_{s m}
$$

The emissivity (or infrared absorptance) $\left(\varepsilon_{m}\right)$ and the longwave transmittance $\left(\tau_{l m}\right)$ of the plastic film mulch were determined by parameter calibration. The longwave reflectance $\left(\rho_{l m}\right)$ of the black film mulch and transparent film mulch are about 0.01 and 0.13 , respectively [27].

\section{Net Radiation of the Soil Surface}

The shortwave reflectance $\left(\rho_{s s}\right)$ and emissivity (or infrared absorptance) $\left(\varepsilon_{s}\right)$ of soil were determined by parameter calibration. According to Campbell and Norman (page 164) [48] the emissivity of sky $\left(\varepsilon_{\text {sky }}\right)$ is defined as follows:

$$
\varepsilon_{\text {sky }}=9.2 \times 10^{-6} \mathrm{~T}_{a}{ }^{2}
$$

\subsubsection{Parameterization for Latent Heat Flux}

The air temperature $\left(T_{\mathrm{a}}\right)$, actual atmospheric pressure $(P)$, and relative humidity $(R H)$ were monitored with weather station. According to Maiti et al. [49] the density of air $\left(\rho_{a}\right)$ can be calculated as follows:

$$
\rho_{a}=\rho_{0} \frac{273}{273+T_{a}}
$$

where $\rho_{0}$ (the air density at $0{ }^{\circ} \mathrm{C}$ and $0.1013 \mathrm{Mpa}$ ) is about $1.29 \mathrm{~kg} / \mathrm{m}^{3}$. According to Allen et al. [50], the psychrometric constant $(\gamma)$, the slope of the vapour pressure curve $(\Delta)$, the saturation vapour pressure $\left(e_{s}\right)$, and the actual vapour pressure $\left(e_{a}\right)$ can be expressed as follows:

$$
\begin{gathered}
\gamma=0.665 \times 10^{-3} \mathrm{P} \\
\Delta=\frac{4098\left[0.6108 \exp \left(\frac{17.27 T_{a}}{T_{a}+237.3}\right)\right]}{\left(T_{a}+237.3\right)^{2}} \\
e_{S}\left(T_{a}\right)=0.6108 \exp \left(\frac{17.27 T_{a}}{T_{a}+237.3}\right) \\
e_{a}=\frac{e_{s}\left(T_{\min }\right) \frac{R H_{\max }}{100}+e_{s}\left(T_{\max }\right) \frac{R H_{\min }}{100}}{2}
\end{gathered}
$$

where $T_{\min }$ and $T_{\max }$ are the minimum and maximum air temperature at a certain period of time $\left({ }^{\circ} \mathrm{C}\right)$, respectively; $e_{s}\left(T_{\min }\right)$ and $e_{s}\left(T_{\max }\right)$ are the saturation vapour pressure at $T_{\min }$ and $T_{\max }(\mathrm{kPa})$, respectively; $R H_{\min }$ and $R H_{\max }$ are the minimum and maximum relative humidity (\%), respectively. 
The mean stomatal resistance $\left(r_{S T}\right)$ and the mean boundary layer resistance $\left(r_{b}\right)$ of the potato canopy were determined through parameter calibration with field experiment data.

As the direct measurement of leaf area index $(L A I)$ is destructive and time consuming, the daily $L A I$ was determined by the fraction of intercepted photosynthetically active radiation $\left(I_{p a r}\right)$ indirectly. According to Haverkort et al. [47] and Boyd et al. [51] the relationship between $I_{p a r}$ and LAI can be expressed as follows:

$$
I_{p a r}=1-e^{-\kappa L A I}
$$

where $\kappa$ is the extinction coefficient. The $\kappa$ can be determined through the measured $T_{p a r}$ and LAI. In this experiment $\kappa$ is 0.92 , close to the result of Spitters [52]. The relationship between the photosynthetically active radiation transmittance $\left(T_{p a r}\right)$ and $I_{p a r}$ is:

$$
T_{p a r}=1-I_{p a r}
$$

\subsubsection{Parameterization for Sensible Heat Flux}

The wind speed at the reference height $(u)$ was monitored with the weather station. The plant height $\left(h_{p}\right)$ was determined using interpolation method with plant height measured in the field.

The reference height $\left(h_{r}\right)$ was $2 \mathrm{~m}$. The roughness height $\left(z_{0}{ }^{\prime}\right)$ is $0.01 \mathrm{~m}$ [43]. The eddy diffusivity decay constant $(n)$ is 2.5 and the von Kármán's constant $(k)$ is 0.41 [43].

\subsubsection{Parameterization for Soil Heat Flux}

The temperature $\left(T_{l}\right)$ of the first vertical node above the soil surface was monitored with sensors. The distance $(\Delta z)$ between the soil surface and the first vertical node was assumed to be $0.1 \mathrm{~m}$ and the time step increment $(\Delta t)$ was $3600 \mathrm{~s}$.

\subsubsection{Parameterization for Heat Conduction}

The air thermal conductivity $\left(k_{a}\right)$ is about $0.025 \mathrm{~W} /\left(\mathrm{m}^{\circ} \mathrm{C}\right)([48]$; page 118 , Table 8.2). The Nusselt number $\left(N_{u d}\right)$ is $1[6]$. The distance $\left(z_{g}\right)$ between the plastic film mulch and soil was determined through parameter calibration or measurement with field experiment data.

The parameterization for the net radiation is shown in Table 1. The parameterizations for the latent heat flux, sensible heat flux, soil heat flux, and heat conduction are shown in Table 2.

Table 1. Input parameters for the net radiation calculation using in modeling the interaction of plastic

\begin{tabular}{|c|c|c|c|}
\hline Symbol & Description & Value & Source \\
\hline \multicolumn{4}{|l|}{ Canopy } \\
\hline$P_{c c}$ & Canopy coverage & Measured in the field & Digital camera \\
\hline$R_{S}$ & Global radiation & Measured in the field & Meteorological station \\
\hline$\alpha_{s c}$ & Shortwave absorptance of plant canopy & Calculated & \\
\hline$\varepsilon_{c}$ & Emissivity (or infrared absorptance) of plant canopy & Calculated & \\
\hline$\rho_{l c}$ & Longwave reflectance of plant canopy & 0.01 & Tarara [27] \\
\hline$\rho_{s c}$ & Shortwave reflectance of plant canopy & Calculated & \\
\hline$\tau_{l c}$ & Longwave transmittance of plant canopy & Calculated & \\
\hline$\tau_{s c}$ & $\begin{array}{l}\text { Shortwave transmittance of plant canopy } \\
\text { Plastic film mulch }\end{array}$ & Measured in the field & Sunscan \\
\hline \multirow[t]{2}{*}{$\alpha_{s m}$} & Shortwave absorptance of transparent plastic film mulch & $0.01 \sim 0.1$ * & Tarara [27] \\
\hline & Shortwave absorptance of black plastic film mulch & $0.8 \sim 0.98 *$ & Tarara [27] \\
\hline \multirow[t]{2}{*}{$\varepsilon_{m}$} & Emissivity (or infrared absorptance) of transparent plastic film mulch & $0.05 \sim 0.97 *$ & Tarara [27] \\
\hline & Emissivity (or infrared absorptance) of black plastic film mulch & $0.8 \sim 0.98 *$ & Tarara [27] \\
\hline \multirow[t]{2}{*}{$\rho_{l m}$} & Longwave reflectance of transparent plastic film mulch & 0.13 & Tarara [27] \\
\hline & Longwave reflectance of black plastic film mulch & 0.01 & Tarara [27] \\
\hline \multirow[t]{2}{*}{$\rho_{s m}$} & Shortwave reflectance of transparent plastic film mulch & Calculated & Tarara [27] \\
\hline & Shortwave reflectance of black plastic film mulch & Calculated & Tarara [27] \\
\hline \multirow[t]{2}{*}{$\tau_{l m}$} & Longwave transmittance of transparent plastic film mulch & $0.7 \sim 0.9 *$ & Tarara [27] \\
\hline & Longwave transmittance of black plastic film mulch & $0.1 \sim 0.67$ * & Tarara [27] \\
\hline \multirow[t]{2}{*}{$\tau_{s m}$} & Shortwave transmittance of transparent plastic film mulch & $0.8 \sim 0.98 *$ & Tarara [27] \\
\hline & Shortwave transmittance of black plastic film mulch & $0.01 \sim 0.1$ * & Tarara [27] \\
\hline \multicolumn{4}{|c|}{ (1) } \\
\hline$\varepsilon_{s}$ & Emissivity (or infrared absorptance) of soil surface & $0.78 \sim 0.98$ * & Tarara [27] \\
\hline$\rho_{s s}$ & Shortwave reflectance of soil & $0.15 \sim 0.3 *$ & Tarara [27] \\
\hline
\end{tabular}
film mulch and potato canopy growth on soil heat transport.

* The value was calibrated with field experiments. 
Table 2. Input parameters for the latent heat flux, sensible heat flux, soil heat flux, and heat conduction calculations using in modeling the interaction of plastic film mulch and potato canopy growth on soil heat transport.

\begin{tabular}{|c|c|c|c|c|}
\hline Symbol & Description & Value & Units & Source \\
\hline & Latent heat flux & & & \\
\hline$P$ & Actual atmospheric pressure & Measured in the field & $\mathrm{kPa}$ & Meteorological station \\
\hline$R H_{\max }$ & Maximum relative humidity & Measured in the field & $\%$ & Meteorological station \\
\hline$R H_{\min }$ & Minimum relative humidity & Measured in the field & $\%$ & Meteorological station \\
\hline$T_{a}$ & Air temperature & Measured in the field & ${ }^{\circ} \mathrm{C}$ & Meteorological station \\
\hline$T_{\max }$ & Maximum air temperature & Measured in the field & ${ }^{\circ} \mathrm{C}$ & Meteorological station \\
\hline$T_{\min }$ & Minimum air temperature & Measured in the field & ${ }^{\circ} \mathrm{C}$ & Meteorological station \\
\hline$T_{\text {par }}$ & Photosynthetically active radiation transmittance & Measured in the field & - & Sunscan \\
\hline$r_{b}$ & Mean boundary layer resistance & $10 \sim 50$ * & $\mathrm{s} / \mathrm{m}$ & Shuttleworth and Wallace [43] \\
\hline$r_{S T}$ & Mean stomatal resistance & $60 \sim 240$ * & $\mathrm{s} / \mathrm{m}$ & Shuttleworth and Wallace [43] \\
\hline$\rho_{0}$ & $\begin{array}{l}\text { Air density at } 0^{\circ} \mathrm{C} \text { and } 0.1013 \mathrm{Mpa} \\
\text { Sensible heat flux }\end{array}$ & 1.29 & $\mathrm{~kg} / \mathrm{m}^{3}$ & Allen et al. [50] \\
\hline$h_{p}$ & Plant height & Measured in the field & $\mathrm{m}$ & Steel tape \\
\hline$h_{r}$ & Reference height & 2 & $\mathrm{~m}$ & Shuttleworth and Wallace [43] \\
\hline$k$ & Von Kármán's constant & 0.41 & - & Shuttleworth and Wallace [43] \\
\hline$n$ & Eddy diffusivity decay constant & 2.5 & - & Shuttleworth and Wallace [43] \\
\hline$u$ & Wind speed at the reference height & Measured in the field & $\mathrm{m} / \mathrm{s}$ & Meteorological station \\
\hline & Soil heat flux & & & \\
\hline$b_{1}$ & Empirical parameter & 0.243 & $\mathrm{~W} /\left(\mathrm{m}^{\circ} \mathrm{C}\right)$ & Chung and Horton [46] \\
\hline$b_{2}$ & Empirical parameter & 0.393 & $\mathrm{~W} /\left(\mathrm{m}^{\circ} \mathrm{C}\right)$ & Chung and Horton [46] \\
\hline$b_{3}$ & Empirical parameter & 1.534 & $\mathrm{~W} /\left(\mathrm{m}^{\circ} \mathrm{C}\right)$ & Chung and Horton [46] \\
\hline$T_{l}$ & Soil temperature at $\Delta \mathrm{z}$ depth & Measured in the field & ${ }^{\circ} \mathrm{C}$ & Sensors \\
\hline$\Delta t$ & Time step increment & 3600 & $\mathrm{~s}$ & Set in field experiments \\
\hline$\Delta z$ & Distance between the soil surface and the first vertical node & 0.1 & $\mathrm{~m}$ & Set in field experiments \\
\hline$\theta$ & Volumetric soil water content at $\Delta \mathrm{z}$ depth & Measured in the field & $\mathrm{m}^{3} / \mathrm{m}^{3}$ & Sensors \\
\hline$\theta_{n}$ & Solid phase content at $\Delta z$ depth & 0.66 & - & Set in field experiments \\
\hline$\theta_{0}$ & $\begin{array}{l}\text { Organic matter content at } \Delta z \text { depth } \\
\text { Heat conduction }\end{array}$ & 0 & - & Set in field experiments \\
\hline$k_{a}$ & Air thermal conductivity & 0.025 & $\mathrm{~W} /\left(\mathrm{m}^{\circ} \mathrm{C}\right)$ & Campbell and Norman ([48] \\
\hline$N_{u d}$ & Nusselt number reflecting regime of conduction & 1 & - & Ham and Kluitenberg [6] \\
\hline$z_{g}$ & Distance between the plastic film mulch and soil & $0.001 \sim 0.01$ * & $\mathrm{m}$ & Ham and Kluitenberg [6] \\
\hline
\end{tabular}

* The value was calibrated with field experiments.

\subsection{Numerical Solution of the Energy Balance Equations}

After the parameterization, the energy balance equations were functions of $T_{\mathcal{C}}, T_{m}$, and $T_{\mathcal{S}}$. Equations (31)-(33) can be expressed as a nonlinear equation group $F(T)$ as follows:

$$
F(T)=\left\{\begin{array}{l}
f_{1}\left(T_{c}, T_{m}, T_{s}\right)=0 \\
f_{2}\left(T_{c}, T_{m}, T_{s}\right)=0 \\
f_{3}\left(T_{c}, T_{m}, T_{s}\right)=0
\end{array}\right.
$$

The equation group (47) can be solving by Newton-Raphson iteration technique [6]. The partial derivatives of the iteration technique can be described as a Jacobian matrix $F^{\prime}(T)$ as follows [6]:

$$
F^{\prime}(T)=\left[\begin{array}{l}
\frac{\partial f_{1}(T)}{\partial T_{c}} \frac{\partial f_{1}(T)}{\partial T_{m}} \frac{\partial f_{1}(T)}{\partial T_{s}} \\
\frac{\partial f_{2}(T)}{\partial T_{\mathcal{C}}} \frac{\partial f_{2}(T)}{\partial T_{m}} \frac{\partial f_{2}(T)}{\partial T_{s}} \\
\frac{\partial f_{3}(T)}{\partial T_{c}} \frac{\partial f_{3}(T)}{\partial T_{m}} \frac{\partial f_{3}(T)}{\partial T_{s}}
\end{array}\right]
$$

where:

$$
\begin{gathered}
\frac{\partial f_{1}(T)}{\partial T_{c}}=4 \varepsilon_{c} \sigma T_{c}^{3}\left(\rho_{l m} \varepsilon_{c}-2\right)-\rho_{a} c_{p} / r_{a}^{a}-\frac{\rho_{a} c_{p}}{\gamma} \Delta /\left(r_{s}^{c}+r_{a}^{c}\right)-\rho_{a} c_{p} / r_{a}^{m} \\
\frac{\partial f_{1}(T)}{\partial T_{m}}=4 \varepsilon_{c} \varepsilon_{m} \sigma T_{m}^{3}+\rho_{a} c_{p} / r_{a}^{m} \\
\frac{\partial f_{1}(T)}{\partial T_{s}}=4 \varepsilon_{c} \tau_{l m} \varepsilon_{s} \sigma T_{s}^{3} \\
\frac{\partial f_{2}(T)}{\partial T_{c}}=4 \varepsilon_{m} \varepsilon_{c} \sigma T_{c}^{3}\left[1+\left(1-\varepsilon_{s}\right) \tau_{l m}\right]+\rho_{a} c_{p} / r_{a}^{m}
\end{gathered}
$$




$$
\begin{gathered}
\frac{\partial f_{2}(T)}{\partial T_{m}}=4 \varepsilon_{m} \sigma T_{m}^{3}\left[\rho_{l c} \varepsilon_{m}+\left(1-\varepsilon_{s}\right) \varepsilon_{m}-2\right]-\rho_{a} c_{p} / r_{a}^{m}-1 / r_{c} \\
\frac{\partial f_{2}(T)}{\partial T_{s}}=4 \varepsilon_{m} \varepsilon_{s} \sigma T_{s}^{3}\left(1+\rho_{l c} \tau_{l m}\right)+1 / r_{c} \\
\frac{\partial f_{3}(T)}{\partial T_{c}}=4 \varepsilon_{s} \tau_{l m} \varepsilon_{c} \sigma T_{c}^{3} \\
\frac{\partial f_{3}(T)}{\partial T_{m}}=4 \varepsilon_{s} \varepsilon_{m} \sigma T_{m}^{3}+1 / r_{c} \\
\frac{\partial f_{3}(T)}{\partial T_{s}}=4 \varepsilon_{s} \sigma T_{s}^{3}\left(\varepsilon_{s} \rho_{l m}-1\right)-1 / r_{c}-\lambda(\theta) / \Delta z-C(\theta) \Delta z /(2 \Delta t)
\end{gathered}
$$

\subsection{Statistical Analysis}

To evaluate the model performance three statistical parameters, including root mean square errors (RMSE), coefficient of determination $\left(R^{2}\right)$, and mean errors (ME) were applied during model calibration and validation. These statistical parameters were calculated from simulated and measured temperatures, soil heat fluxes, and net radiations using the equations as follows:

$$
\begin{gathered}
R M S E=\sqrt{\frac{1}{N} \sum_{i=1}^{N}\left(O_{i}-P_{i}\right)^{2}} \\
R^{2}=\left[\frac{\sum_{i=1}^{N}\left(O_{i}-\bar{O}\right)\left(P_{i}-\bar{P}\right)}{\sqrt{\sum_{i=1}^{N}\left(O_{i}-\bar{O}\right)^{2}} \sqrt{\sum_{i=1}^{N}\left(P_{i}-\bar{P}\right)^{2}}}\right]^{2} \\
M E=\frac{1}{N} \sum_{i=1}^{N}\left(O_{i}-P_{i}\right)
\end{gathered}
$$

where $\mathrm{O}_{\mathrm{i}}$ and $\mathrm{P}_{\mathrm{i}}$ are the observed and simulated values, respectively; $\bar{O}$ and $\bar{P}$ are the averages of the observed and simulated values, respectively; and $\mathrm{N}$ is the number of observations.

\section{Results and Discussion}

The $P_{c c}$ (fractional canopy coverage) and $T_{p a r}$ (photosynthetically active radiation transmittance of the potato canopy) were measured to reflect the potato canopy growth (Figure 5; Figure 6). The black plastic film mulch had greater plant canopy in the BM treatment than in the TM treatment in 2014 and 2015. It might be caused by the higher air temperature near the black mulch surface [11].

\subsection{Model Calibration and Validation}

Model parameters were calibrated with the temperature of the plant canopy $\left(T_{c}\right)$, the temperature of the plastic film mulch $\left(T_{m}\right)$, the temperature of the soil surface $\left(T_{s}\right)$, the net radiation $\left(R_{n}\right)$, and the soil heat flux $(G)$ which were measured in the potato field in 2014. The calibrated parameters for the transparent and black plastic film mulch treatments are shown in Table 3. The calibrated model was validated with $T_{\mathcal{c}}, T_{m}, T_{s}, R_{n}$, and $G$ measured in the potato field in 2015. 


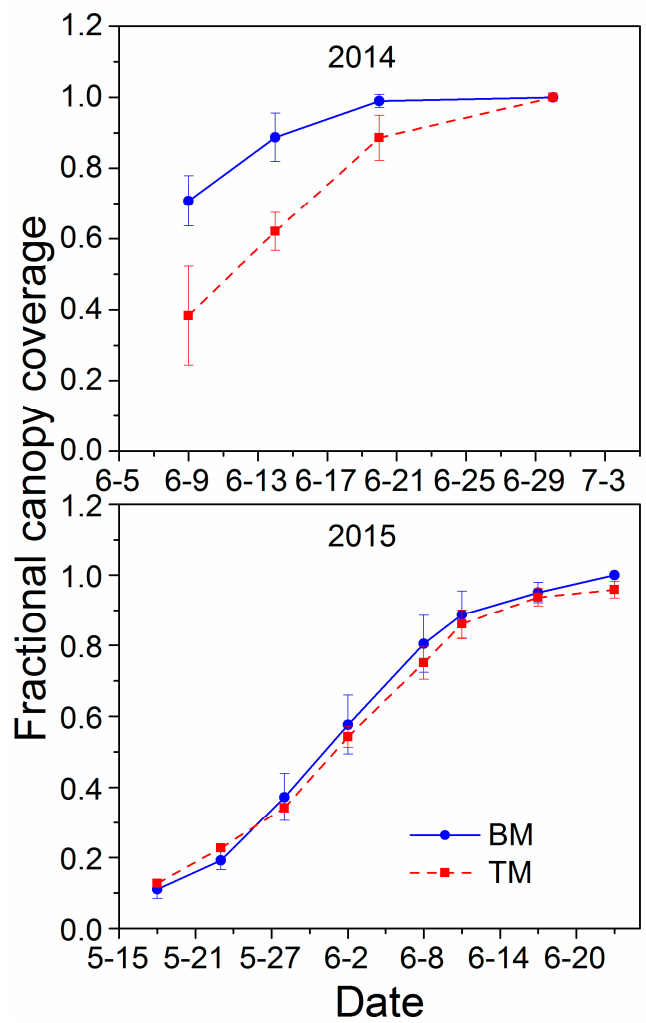

Figure 5. Fractional canopy coverage by potato grown with transparent plastic film (TM) and black plastic film (BM) treatments at Wuwei, China, in 2014 and 2015.

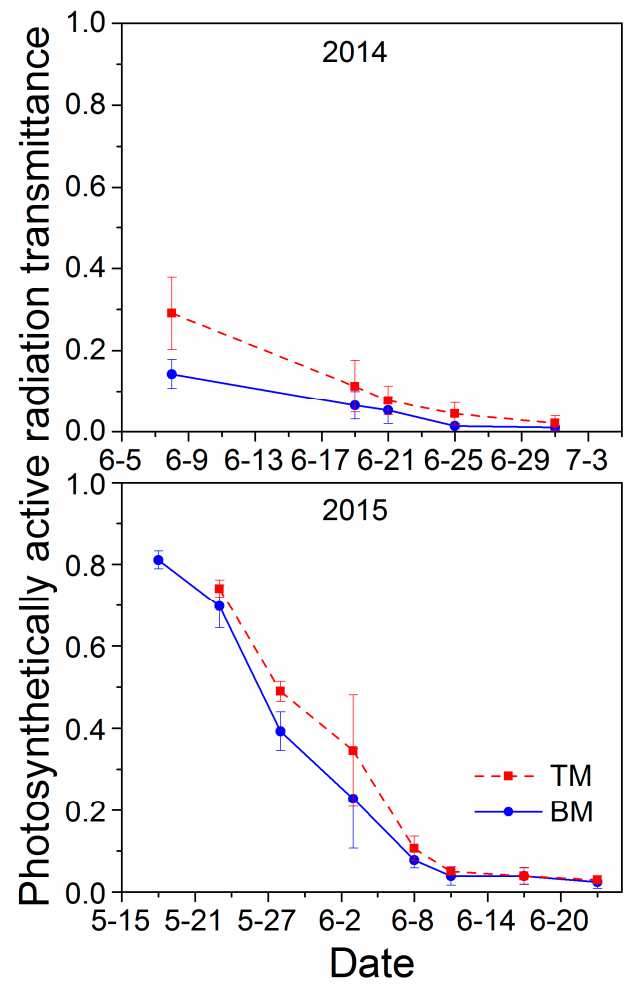

Figure 6. Photosynthetically active radiation transmittance of the transparent plastic film mulch (TM) treatment and black plastic film mulch (BM) treatment for potato production at Wuwei, China, in 2014 and 2015. 
Table 3. The model parameters (shortwave transmittance $\tau_{s m}$, shortwave absorptance $\alpha_{s m}$, emissivity $\varepsilon_{m}$, and longwave transmittance $\tau_{l m}$ of the plastic film mulch; emissivity $\varepsilon_{S}$ and shortwave reflectance $\rho_{S S}$ of soil; mean stomatal resistance $r_{S T}$, mean boundary layer resistance $r_{b}$; and distance between the plastic film mulch and soil $z_{g}$ ) calibrated with hourly temperature, net radiation, and soil heat flux measured for the transparent plastic film mulch (TM) and black plastic film mulch (BM) in the potato field at Wuwei, China in 2014.

\begin{tabular}{cccccccccc}
\hline Treatment & $\tau_{s m}$ & $\alpha_{s m}$ & $\varepsilon_{m}$ & $\tau_{l m}$ & $\varepsilon_{s}$ & $\rho_{s s}$ & $r_{S T}(\mathbf{s} / \mathbf{m})$ & $r_{b}(\mathbf{s} / \mathbf{m})$ & $z_{g}(\mathrm{~m})$ \\
\hline $\mathrm{TM}$ & 0.93 & 0.05 & 0.38 & 0.72 & 0.86 & 0.17 & 90 & 35 & 0.004 \\
$\mathrm{BM}$ & 0.03 & 0.93 & 0.82 & 0.11 & 0.86 & 0.17 & 90 & 35 & 0.004 \\
\hline
\end{tabular}

\subsection{Model Calibration and Validation for Temperature}

Generally, the model can reflect the daily fluctuations of mulch surface temperature and soil surface temperature for the TM and BM treatments by comparing the simulated and observed temperatures (Figures 7 and 8; Table 4; Table 5). In 2015, the daily RMSE of soil surface temperature for the TM and BM treatments, which were smaller than the hourly RMSE, were 2.8 and $1.5^{\circ} \mathrm{C}$, respectively. This result was similar with Ham and Kluitenberg [6] who reported that the RMSE of soil temperature was $2.4{ }^{\circ} \mathrm{C}$ for the TM treatment and $1.8^{\circ} \mathrm{C}$ for the BM treatment. In 2014 and 2015 , the hourly and daily $R^{2}$ of temperatures ranged from 0.65 to 0.84 and 0.76 to 0.91 , respectively.

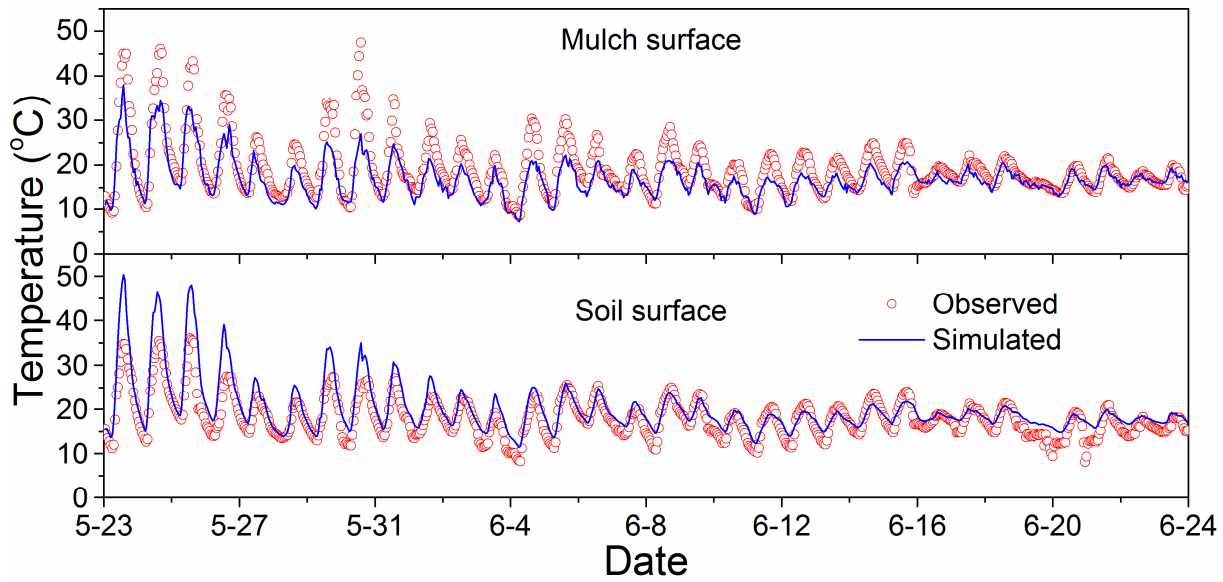

Figure 7. Comparison of the observed and simulated hourly temperatures on the transparent plastic film mulch (TM) surface and soil surface at Wuwei, China, in 2015.

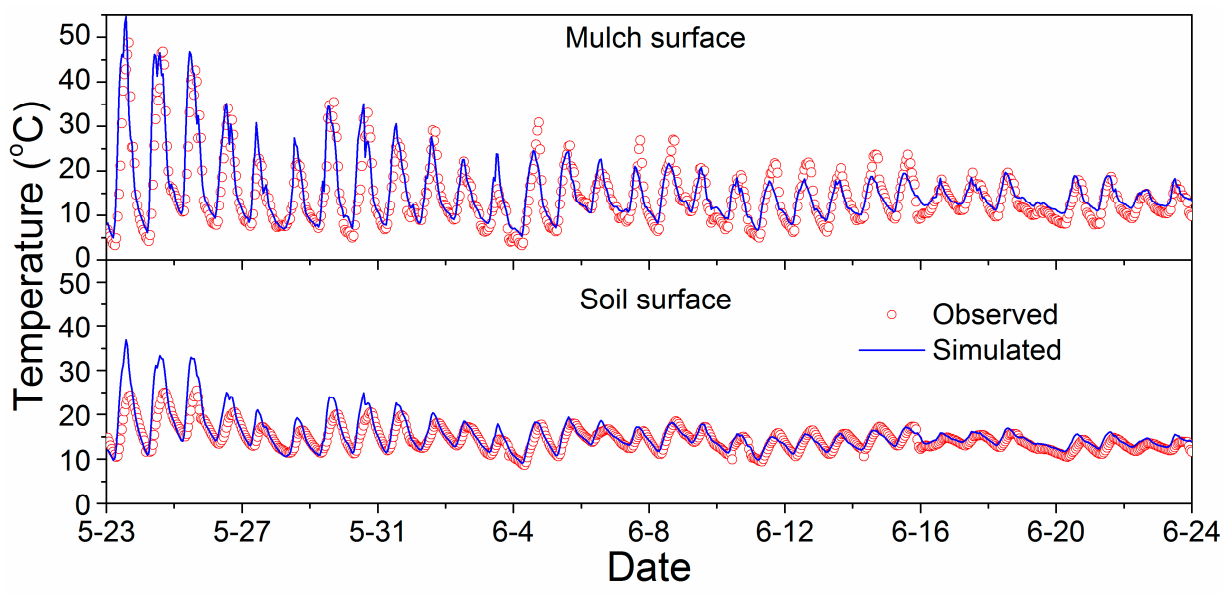

Figure 8. Comparison of the observed and simulated hourly temperature on the black plastic film mulch (BM) surface and soil surface at Wuwei, China, in 2015. 
Table 4. The root mean square errors (RMSE), coefficient of determination $\left(R^{2}\right)$, and mean errors (ME) in simulated and observed hourly temperatures on the mulch surface and soil surface for transparent plastic film mulch and black plastic film mulch treatments at Wuwei, China.

\begin{tabular}{cccccc}
\hline \multirow{2}{*}{ Season } & \multirow{2}{*}{ Parameters } & \multicolumn{2}{c}{ Transparent Plastic Film Mulch } & \multicolumn{2}{c}{ Black Plastic Film Mulch } \\
\cline { 3 - 6 } & & Mulch Surface & Soil Surface & Mulch Surface & Soil Surface \\
\hline \multirow{3}{*}{2014} & $\mathrm{RMSE}\left({ }^{\circ} \mathrm{C}\right)$ & 3.5 & 2.5 & 4.4 & 3.8 \\
& $R^{2}$ & 0.80 & 0.79 & 0.84 & 0.82 \\
& $\mathrm{ME}\left({ }^{\circ} \mathrm{C}\right)$ & 2.2 & -0.9 & 4.0 & 3.6 \\
2015 & $\mathrm{RMSE}\left({ }^{\circ} \mathrm{C}\right)$ & 3.8 & 3.5 & 4.1 & 2.7 \\
& $R^{2}$ & 0.82 & 0.79 & 0.73 & 0.65 \\
& $\mathrm{ME}\left({ }^{\circ} \mathrm{C}\right)$ & 2.2 & -2.2 & -1.1 & -1.1 \\
\hline
\end{tabular}

Table 5. The root mean square errors (RMSE) and coefficient of determination $\left(R^{2}\right)$ in simulated and observed daily temperatures (on mulch surface and soil surface) for the transparent plastic film mulch and black plastic film mulch treatments at Wuwei, China.

\begin{tabular}{cccccc}
\hline \multirow{2}{*}{ Season } & \multirow{2}{*}{ Parameters } & \multicolumn{2}{c}{ Transparent Plastic Film Mulch } & \multicolumn{2}{c}{ Black Plastic Film Mulch } \\
\cline { 3 - 6 } & & Mulch Surface & Soil Surface & Mulch Surface & Soil Surface \\
\hline \multirow{2}{*}{2014} & RMSE $\left({ }^{\circ} \mathrm{C}\right)$ & 2.4 & 1.4 & 4.2 & 3.7 \\
& $R^{2}$ & 0.83 & 0.84 & 0.76 & 0.86 \\
2015 & ${\operatorname{RMSE~}\left({ }^{\circ} \mathrm{C}\right)}_{R^{2}}$ & 0.6 & 2.8 & 1.7 & 1.5 \\
& & 0.78 & 0.83 & 0.87 & 0.91 \\
\hline
\end{tabular}

During the early plant growth stage (23 May to 27 May), the simulations were not satisfactory (Figures 7 and 8). The larger simulation deviation might be caused by the neglect of soil evaporation from the hole $(8 \mathrm{~cm}$ in diameter) of the plant emergence. Moreover, the temperature sensors on the mulch surface were affected by solar radiation during the early plant growth stage, which might also cause the deviation. As the plant canopy got larger, the simulation got better during the later plant growth stages. The variations of mulch surface temperature and soil surface temperature were smaller during later potato growth because of the larger area shaded by the plant canopy. Generally, the model could simulate the daily temperature variations at different potato growth stages for different plastic film mulch treatments.

\subsection{Model Calibration and Validation for Net Radiation and Soil Heat Flux}

The hourly simulated and observed net radiation for the TM and BM treatments were compared and the statistical hourly and daily RMSE, $R^{2}$, and ME were calculated (Figure 9 and Table 6; Table 7). The daily simulation of net radiation was reasonably good with daily RMSE for the TM and BM treatments 20.30 and $32.79 \mathrm{~W} / \mathrm{m}^{2}$ during validation, respectively. The ME of daily net radiation for the two treatments ranged from 12.96 to $36.14 \mathrm{~W} / \mathrm{m}^{2}$ in 2014 and 2015 . The $R^{2}$ ranged from 0.89 to 0.98, which was greater than 0.8, a typical value for model performance according to Baldocchi and Wilson [53]. An under-estimation of net radiation for the TM treatment and over-estimation for the BM treatment were observed at noon in 2015 (Figure 9). Despite the simulation deviations, the model reflected the daily fluctuations of net radiation during different growth stages of potato growth.

Generally, the model reflected the daily variation of soil heat flux with daily RMSE of the TM and $\mathrm{BM}$ treatments ranging from 17.03 to $25.27 \mathrm{~W} / \mathrm{m}^{2}$ and $\mathrm{ME}$ ranging from -11.30 to $23.35 \mathrm{~W} / \mathrm{m}^{2}$ during the calibration and validation presses (Figure 10 and Table 6; Table 7). However, the hourly and daily $R^{2}$ of soil heat flux were rather small. This might be caused by some abnormal values during soil heat flux measurement. 


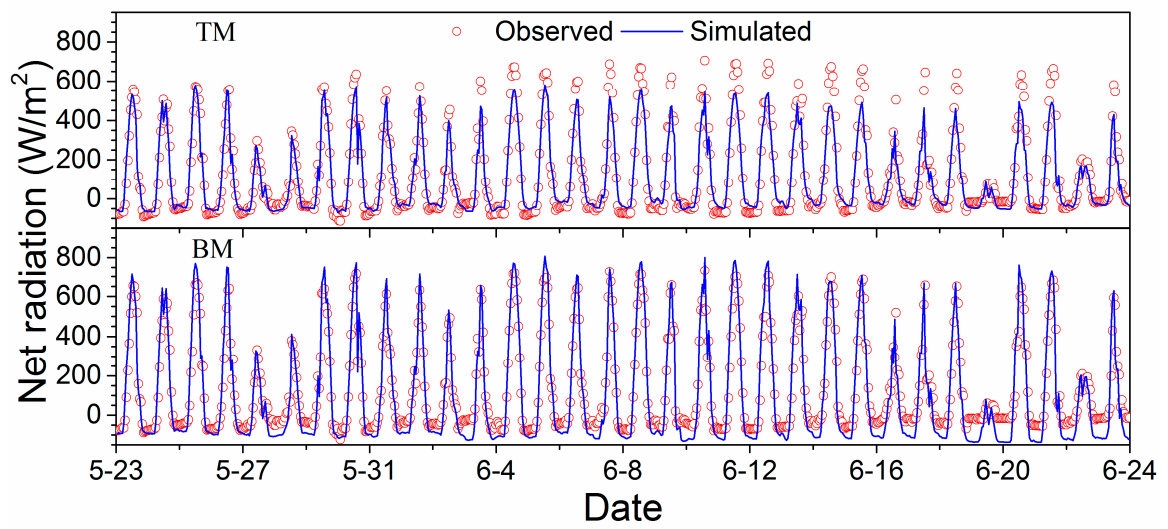

Figure 9. Comparison of the observed and simulated hourly net radiation of the transparent plastic film mulch (TM) treatment and black plastic film mulch (BM) treatment at Wuwei, China, in 2015.

Table 6. The root mean square errors (RMSE), coefficient of determination $\left(R^{2}\right)$, and mean errors (ME) in simulated and observed hourly net radiation and soil heat flux for the transparent plastic film mulch and black plastic film mulch treatments at Wuwei, China.

\begin{tabular}{cccccc}
\hline \multirow{2}{*}{ Season } & \multirow{2}{*}{ Parameters } & \multicolumn{2}{c}{ Transparent Plastic Film Mulch } & \multicolumn{2}{c}{ Black Plastic Film Mulch } \\
\cline { 3 - 6 } & & Net Radiation & Soil Heat Flux & Net Radiation & Soil Heat Flux \\
\hline \multirow{3}{*}{2014} & RMSE $\left(\mathrm{W} / \mathrm{m}^{2}\right)$ & 66.47 & 28.73 & 64.93 & 23.47 \\
& $R^{2}$ & 0.98 & 0.89 & 0.97 & 0.67 \\
& $\mathrm{ME}\left(\mathrm{W} / \mathrm{m}^{2}\right)$ & 20.84 & -11.30 & 36.14 & 20.22 \\
\multirow{2}{*}{2015} & $\mathrm{RMSE}\left(\mathrm{W} / \mathrm{m}^{2}\right)$ & 71.84 & 42.83 & 83.83 & 39.67 \\
& $R^{2}$ & 0.92 & 0.63 & 0.92 & 0.56 \\
& $\mathrm{ME}\left(\mathrm{W} / \mathrm{m}^{2}\right)$ & 12.96 & -18.43 & 20.12 & 23.35 \\
\hline
\end{tabular}

Table 7. The root mean square errors (RMSE) and coefficient of determination $\left(R^{2}\right)$ in simulated and observed daily net radiation and soil heat flux for the transparent plastic film mulch and black plastic film mulch treatments at Wuwei, China.

\begin{tabular}{cccccc}
\hline \multirow{2}{*}{ Season } & \multirow{2}{*}{ Parameters } & \multicolumn{2}{c}{ Transparent Plastic Film Mulch } & \multicolumn{2}{c}{ Black Plastic Film Mulch } \\
\cline { 3 - 6 } & & Net Radiation & Soil Heat Flux & Net Radiation & Soil Heat Flux \\
\hline \multirow{2}{*}{2014} & RMSE $\left(\mathrm{W} / \mathrm{m}^{2}\right)$ & 26.57 & 17.03 & 41.13 & 20.63 \\
& $R^{2}$ & 0.92 & 0.52 & 0.96 & 0.62 \\
\multirow{2}{*}{2015} & & & & 32.79 & 25.27 \\
& RMSE $\left(\mathrm{W} / \mathrm{m}^{2}\right)$ & 20.30 & 23.42 & 0.93 & 0.36 \\
\hline
\end{tabular}

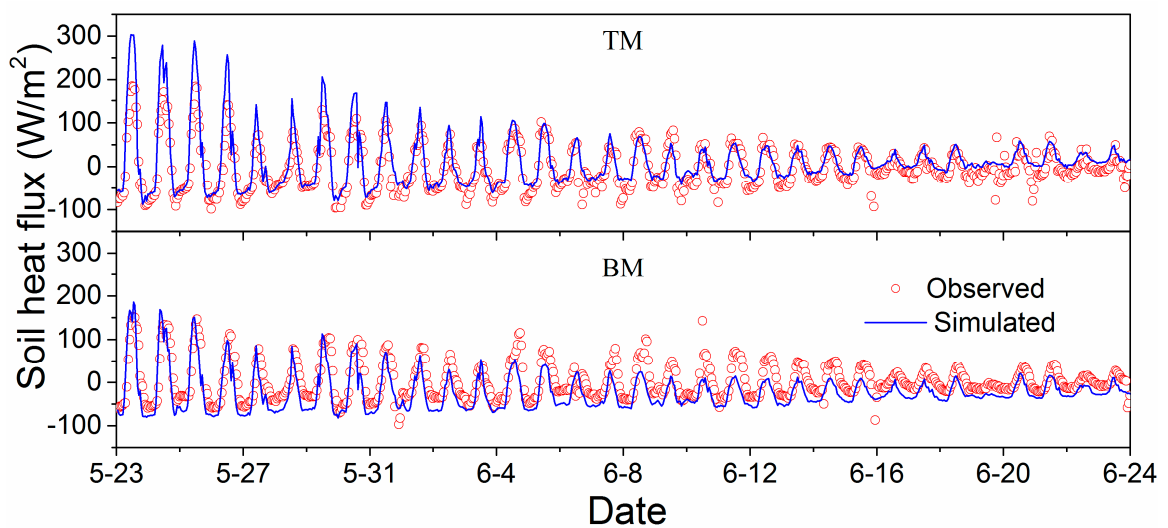

Figure 10. Comparison of the observed and simulated hourly soil heat flux of the transparent plastic film mulch (TM) treatment and black plastic film mulch (BM) treatment at Wuwei, China, in 2015. 


\subsection{Canopy Temperature Analysis With the Model}

The canopy temperature can affect the aboveground plant growth, especially during the early plant growth stage $[11,54]$. The canopy temperature was estimated with the calibrated model for the TM and BM treatments in 2015 (Figure 11). The canopy temperature of the BM treatment was greater than for the TM treatment. The maximum temperature difference between the TM and BM treatments could be as much as $7{ }^{\circ} \mathrm{C}$ during early potato growth. The higher canopy temperature in the BM treatment could be the reason why the aboveground growth in the BM treatment was greater than in the TM treatment $[5,11]$. The model could be a useful tool to study the spatiotemporal distribution of temperature, net radiation, and soil heat flux in potato field with different plastic film mulches and their effects on potato growth during different growth stages.

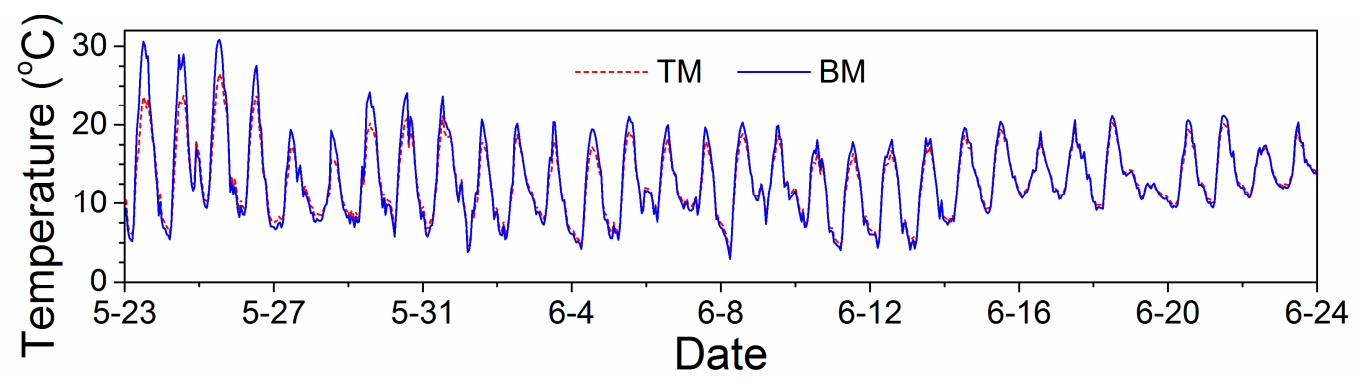

Figure 11. Simulated hourly canopy temperature of potato plants grown with transparent plastic film mulch (TM) and black plastic film mulch (BM) at Wuwei, China, in 2015.

\section{Summary and Conclusions}

A numerical model was developed to simulate the heat transport in potato field with full plastic film mulch in an arid area. This model predicted the interaction of potato plant growth and the optical properties of plastic film mulch on heat transport by utilizing the leaf area index, canopy coverage, photosynthetically active radiation transmittance, and considering the radiation transfer in atmosphere-canopy-mulch-soil system. The heat transfer parameters (net radiation, mulch surface temperature, soil surface temperature, and soil heat flux) were measured in the field experiments in 2014 and 2015 growing seasons in potato field with two conventional plastic film mulch treatments (TM and BM treatments) to calibrate (2014) and validate (2015) the model.

Generally, the temperature simulation was reasonably good with daily RMSE of soil surface temperature 2.8 and $1.5^{\circ} \mathrm{C}$ for the TM and BM treatments, respectively. The model reflected the daily temperature variations during different potato growth stages except during early plant growth. Moreover, the model simulated the daily fluctuations of net radiation with daily RMSE for the TM and $\mathrm{BM}$ treatments 20.30 and $32.79 \mathrm{~W} / \mathrm{m}^{2}$ during validation, respectively. The daily $R^{2}$ of net radiation ranged from 0.89 to 0.98 , while the daily $R^{2}$ of soil heat flux were small because of some abnormal values during soil heat flux measurement. The simulation showed that the BM treatment had higher canopy temperature than the TM treatment. The maximum canopy temperature difference between $\mathrm{TM}$ and $\mathrm{BM}$ treatments could be as high as $7^{\circ} \mathrm{C}$ during early potato growth.

In conclusion, the model could give an explanation for the interaction of plastic film mulch and potato canopy growth on heat transport. The model can be used to simulate heat transport in potato fields with different plastic film mulches in semiarid areas. The heat conditions simulation can provide guidance in plastic film choosing for potato cultivation to avoid heat stress. One of the limitations to study in the future is the cause of the simulation deviations, especially during early crop growth.

Author Contributions: Data curation, Y.-L.Z.; Formal analysis, Y.-L.Z.; Funding acquisition, F.-X.W. and Y.-L.Z.; Methodology, Y.-L.Z. and F.-X.W.; Software, Y.-L.Z.; Supervision, F.-X.W.; Writing-original draft, Y.-L.Z.; Writing-review \& editing, F.-X.W., C.C.S. and S.-Y.F. All authors have read and agreed to the published version of the manuscript. 
Funding: This study was supported financially by the National Natural Science Foundation of China (51579240, 51809225), the Ministry of Water Resources of China (201501017), and the Natural Science Foundation of Jiangsu Province, China (BK20180929).

Conflicts of Interest: The authors declare no conflict of interest.

\section{References}

1. Li, F.M.; Wang, J.; Xu, J.Z.; Xu, H.L. Productivity and soil response to plastic film mulching durations for spring wheat on entisols in the semiarid loess plateau of China. Soil Tillage Res. 2004, 78, 9-20. [CrossRef]

2. Bonachela, S.; Granados, M.R.; López, J.C.; Hernández, J.; Magán, J.J.; Baeza, E.J.; Baille, A. How plastic mulches affect the thermal and radiative microclimate in an unheated low-cost greenhouse. Agric. For. Meteorol. 2012, 152, 65-72. [CrossRef]

3. Cavero, J.; Ortega, R.G.; Zaragoza, C. Clear plastic mulch improved seedling emergence of direct-seeded pepper. Hortscience 1996, 31, 70-73. [CrossRef]

4. Chellemi, D.O.; Olson, S.M.; Mitchell, D.J.; Secker, I.; McSorley, R. Adaptation of soil solarization to the integrated management of soilborne pests of tomato under humid conditions. Phytopathology 1997, 87, 250-258. [CrossRef] [PubMed]

5. Decoteau, D.R.; Kasperbauer, M.J.; Daniels, D.D.; Hunt, P.G. Plastic mulch color effects on reflected light and tomato plant growth. Sci. Hortic. 1988, 34, 169-175. [CrossRef]

6. Ham, J.M.; Kluitenberg, G.J. Modeling the effect of mulch optical properties and mulch-soil contact resistance on soil heating under plastic mulch culture. Agric. For. Meteorol. 1994, 71, 403-424. [CrossRef]

7. Hou, X.Y.; Wang, F.X.; Han, J.J.; Kang, S.Z.; Feng, S.Y. Duration of plastic mulch for potato growth under drip irrigation in an arid region of northwest China. Agric. For. Meteorol. 2010, 150, 115-121. [CrossRef]

8. Liakatas, A.; Clark, J.A.; Monteith, J.L. Measurements of the heat balance under plastic mulches. Part I. Radiation balance and soil heat flux. Agric. For. Meteorol. 1986, 36, 227-239. [CrossRef]

9. Liu, C.A.; Jin, S.L.; Zhou, L.M.; Jia, Y.; Li, F.M.; Xiong, Y.C.; Li, X.G. Effects of plastic film mulch and tillage on maize productivity and soil parameters. Eur. J. Agron. 2009, 31, 241-249. [CrossRef]

10. Qin, S.J.; Li, S.E.; Yang, K.; Hu, K.L. Can plastic mulch save water at night in irrigated croplands? J. Hydrol. 2018, 564, 667-681. [CrossRef]

11. Zhang, Y.L.; Wang, F.X.; Shock, C.C.; Yang, K.J.; Kang, S.Z.; Qin, J.T.; Li, S.E. Effects of plastic mulch on the radiative and thermal conditions and potato growth under drip irrigation in arid northwest China. Soil Tillage Res. 2017, 172, 1-11. [CrossRef]

12. Anikwe, M.A.N.; Mbah, C.N.; Ezeaku, P.I.; Onyia, V.N. Tillage and plastic mulch effects on soil properties and growth and yield of cocoyam (colocasia esculenta) on an ultisol in southeastern Nigeria. Soil Till. Res. 2007, 93, 264-272. [CrossRef]

13. Liang, S.M.; Ren, C.; Wang, P.J.; Wang, X.T.; Li, Y.S.; Xu, F.H.; Wang, Y.; Dai, Y.Q.; Zhang, L.; Li, X.P.; et al. Improvements of emergence and tuber yield of potato in a seasonal spring arid region using plastic film mulching only on the ridge. Field Crops Res. 2018, 223, 57-65. [CrossRef]

14. Gao, Y.H.; Xie, Y.P.; Jiang, H.Y.; Wu, B.; Niu, J.Y. Soil water status and root distribution across the rooting zone in maize with plastic film mulching. Field Crops Res. 2014, 156, 40-47. [CrossRef]

15. Zhang, Y.L.; Wang, F.X.; Shock, C.C.; Yang, K.J.; Kang, S.Z.; Qin, J.T.; Li, S.E. Influence of different plastic film mulches and wetted soil percentages on potato grown under drip irrigation. Agric. Water Manag. 2017, 180, 160-171. [CrossRef]

16. Kasirajan, S.; Ngouajio, M. Polyethylene and biodegradable mulches for agricultural applications: A review. Agron. Sustain. Dev. 2012, 32, 501-529. [CrossRef]

17. Dong, B.D.; Liu, M.Y.; Jiang, J.W.; Shi, C.H.; Wang, X.M.; Qiao, Y.Z.; Liu, Y.Y.; Zhao, Z.H.; Si, F.Y. Growth, grain yield, and water use efficiency of rain-fed spring hybrid millet (Setaria italica) in plastic-mulched and unmulched fields. Agric. Water Manag. 2014, 143, 93-101. [CrossRef]

18. Liu, X.E.; Li, X.G.; Hai, L.; Wang, Y.P.; Li, F.M. How efficient is film fully-mulched ridge-furrow cropping to conserve rainfall in soil at a rainfed site? Field Crops Res. 2014, 169, 107-115. [CrossRef]

19. Qin, S.H.; Zhang, J.L.; Dai, H.L.; Wang, D.; Li, D.M. Effect of ridge-furrow and plastic-mulching planting patterns on yield formation and water movement of potato in a semi-arid area. Agric. Water Manag. 2014, 131, 87-94. [CrossRef] 
20. Zhang, F.; Zhang, W.J.; Qi, J.G.; Li, F.M. A regional evaluation of plastic film mulching for improving crop yields on the Loess Plateau of China. Agric. For. Meteorol. 2018, 248, 458-468. [CrossRef]

21. Zhao, H.; Xiong, Y.C.; Li, F.M.; Wang, R.Y.; Qiang, S.C.; Yao, T.F.; Mo, F. Plastic film mulch for half growing-season maximized WUE and yield of potato via moisture-temperature improvement in a semi-arid agroecosystem. Agric. Water Manag. 2012, 104, 68-78. [CrossRef]

22. Kader, M.A.; Senge, M.; Mojid, M.A.; Ito, K. Recent advances in mulching materials and methods for modifying soil environment. Soil Tillage Res. 2017, 168, 155-166. [CrossRef]

23. Qin, X.L.; Li, Y.Z.; Han, Y.L.; Hu, Y.C.; Li, Y.J.; Wen, X.X.; Liao, Y.C.; Siddique, K.H.M. Ridge-furrow mulching with black plastic film improves maize yield more than white plastic film in dry areas with adequate accumulated temperature. Agric. For. Meteorol. 2018, 262, 206-214. [CrossRef]

24. Ruiz, J.M.; Hernandez, J.; Castilla, N.; Romero, L. Potato performance in response to different mulches. 1. Nitrogen metabolism and yield. J. Agric. Food Chem. 1999, 47, 2660-2665. [CrossRef]

25. Farias-Larios, J.; Orozco-Santos, M. Effect of polyethylene mulch colour on aphid populations, soil temperature, fruit quality, and yield of watermelon under tropical conditions. N. Z. J. Crop Hortic. Sci. 1997, 25, 369-374. [CrossRef]

26. Yaghi, T.; Arslan, A.; Naoum, F. Cucumber (cucumis sativus, L.) water use efficiency (WUE) under plastic mulch and drip irrigation. Agric. Water Manag. 2013, 128, 149-157. [CrossRef]

27. Tarara, J.M. Microclimate modification with plastic mulch. Hortscience 2000, 35, 169-180. [CrossRef]

28. Mahrer, Y. Prediction of soil temperatures of a soil mulched with transparent polyethylene. J. Appl. Meteorol. 1973, 18, 1263-1267. [CrossRef]

29. Mahrer, Y.; Katan, J. Spatial soil temperature regime under transparent polyethylene mulch: Numerical and experimental studies. Soil Sci. 1981, 131, 82-87. [CrossRef]

30. Mahrer, Y.; Naot, O.; Rawitz, E.; Katan, J. Temperature and moisture regimes in soils mulched with transparent polyethylene. Soil Sci. Soc. Am. J. 1984, 48, 362-367. [CrossRef]

31. Wu, C.L.; Chau, K.W.; Huang, J.S. Modelling coupled water and heat transport in a soil-mulch-plant-atmosphere continuum (SMPAC) system. Appl. Math. Model. 2007, 31, 152-169. [CrossRef]

32. Yang, Q.D.; Zuo, H.C.; Xiao, X.; Wang, S.J.; Chen, B.L.; Chen, J.W. Modelling the effects of plastic mulch on water, heat and $\mathrm{CO}_{2}$ fluxes over cropland in an arid region. J. Hydrol. 2012, 452-453, 102-118. [CrossRef]

33. Flerchinger, G.N.; Sauer, T.J.; Aiken, R.A. Effects of crop residue cover and architecture on heat and water transfer at the soil surface. Geoderma 2003, 116, 217-233. [CrossRef]

34. Flerchinger, G.N.; Pierson, F.B. Modeling plant canopy effects on variability of soil temperature and water. Agric. For. Meteorol. 1991, 56, 227-246. [CrossRef]

35. Hijmans, R.J. The effect of climate change on global potato production. Am. J. Potato Res. 2003, 80, 271-280. [CrossRef]

36. Van Dam, J.; Kooman, P.L.; Struik, P.C. Effects of temperature and photoperiod on early growth and final number of tubers in potato (Solanum tuberosum L.). Potato Res. 1996, 39, 51-62. [CrossRef]

37. Rykaczewska, $\mathrm{K}$. The effect of high temperature occurring in subsequent stages of plant development on potato yield and tuber physiological defects. Am. J. Potato Res. 2015, 92, 339-349. [CrossRef]

38. Zhang, Y.L.; Feng, S.Y.; Wang, F.X.; Binley, A. Simulation of soil water flow and heat transport in drip irrigated potato field with raised beds and full plastic-film mulch in a semiarid area. Agric. Water Manag. 2018, 209, 178-187. [CrossRef]

39. Bojacá, C.R.; García, S.J.; Schrevens, E. Analysis of potato canopy coverage as assessed through digital imagery by nonlinear mixed effects models. Potato Res. 2011, 54, 237-252. [CrossRef]

40. Purcell, L.C. Soybean canopy coverage and light interception measurements using digital imagery. Crop Sci. 2000, 40, 834-837. [CrossRef]

41. Giambelluca, T.W.; Scholz, F.G.; Bucci, S.J.; Meinzer, F.C.; Goldstein, G.; Hoffmann, W.A.; Franco, A.C.; Buchert, M.P. Evapotranspiration and energy balance of Brazilian savannas with contrasting tree density. Agric. For. Meteorol. 2009, 149, 1365-1376. [CrossRef]

42. Kang, S.Z.; Liu, X.M.; Xiong, Y.Z. Theory and Application of Water Transport in Soil-Plant-Atmosphere Continuum; Water Conservancy and Electric Power Press: Beijing, China, 1994.

43. Shuttleworth, W.J.; Wallace, J.S. Evaporation from sparse crops-an energy combination theory. Q. J. $R$. Meteor. Soc. 1985, 111, 839-855. [CrossRef] 
44. Horton, R.; Chung, S.O. Soil Heat Flow. In Modeling Plant and Soil Systems; Hanks, J., Ritchie, J., Eds.; American Society of Agronomists: Madison, WI, USA, 1991.

45. de Vries, D.A. The thermal properties of soils. In Physics of Plant Environment; van Wijk, R.W., Ed.; North Holland: Amsterdam, The Netherlands, 1963; pp. 210-235.

46. Chung, S.O.; Horton, R. Soil heat and water flow with a partial surface mulch. Water Resour. Res. 1987, 23, 2175-2186. [CrossRef]

47. Haverkort, A.J.; Uenk, D.; Veroude, H.; van de Waart, M. Relationships between ground cover, intercepted solar radiation, leaf area index and infrared reflectance of potato crops. Potato Res. 1991, 34, 113-121. [CrossRef]

48. Campbell, G.S.; Norman, J.M. An Introduction to Environmental Biophysics, 2nd ed.; Springer-Verlag: New York, NY, USA, 1998.

49. Maiti, S.; Patel, P.; Vyas, K.; Eswaran, K.; Ghosh, P.K. Performance evaluation of a small scale indirect solar dryer with static reflectors during non-summer months in the Saurashtra region of western India. Sol. Energy 2011, 85, 2686-2696. [CrossRef]

50. Allen, R.G.; Pereira, L.S.; Raes, D.; Smith, M. Crop Evapotranspiration: Guidelines for Computing Crop Water Requirements; FAO Irrigation and Drainage Paper No. 56; FAO: Rome, Italy, 1998.

51. Boyd, N.S.; Gordon, R.; Martin, R.C. Relationship between leaf area index and ground cover in potato under different management conditions. Potato Res. 2002, 45, 117-129. [CrossRef]

52. Spitters, C.J.T. An analysis of variation in yield among potato cultivars in terms of light absorption, light utilization and dry matter partitioning. Acta Hortic. 1987, 214, 71-84. [CrossRef]

53. Baldocchi, D.D.; Wilson, K.B. Modeling $\mathrm{CO}_{2}$ and water vapor exchange of a temperate broadleaved forest across hourly to decadal time scales. Ecol. Model. 2001, 142, 155-184. [CrossRef]

54. Ham, J.M.; Kluitenberg, G.J.; Lamont, W.J. Optical properties of plastic mulches affect the field temperature regime. J. Am. Soc. Hortic. Sci. 1993, 118, 188-193. [CrossRef]

(C) 2020 by the authors. Licensee MDPI, Basel, Switzerland. This article is an open access article distributed under the terms and conditions of the Creative Commons Attribution (CC BY) license (http://creativecommons.org/licenses/by/4.0/). 